NBER WORKING PAPER SERIES

\title{
MACROECONOMIC CONDITIONS AND THE PUZZLES OF CREDIT SPREADS AND CAPITAL STRUCTURE
}

\author{
Hui Chen \\ Working Paper 16151 \\ http://www.nber.org/papers/w16151 \\ NATIONAL BUREAU OF ECONOMIC RESEARCH \\ 1050 Massachusetts Avenue \\ Cambridge, MA 02138 \\ July 2010
}

I am very grateful to the members of my dissertation committee, John Cochrane, Doug Diamond, Pietro Veronesi, and especially to the committee chair Monika Piazzesi for constant support and many helpful discussions. I also thank Heitor Almeida, Ravi Bansal, Pierre Collin-Dufresne, Darrel Duffie, Gene Fama, Dirk Hackbarth, Lars Hansen, Campbell Harvey (the editor), Andrew Hertzberg, Francis Longstaff, Erwan Morellec, Jianjun Miao, Stewart Myers, Tano Santos, Martin Schneider, Costis Skiadas, IlyaŞtrebulaev, Suresh Sundaresen, two anonymous referees, and seminar participants at Carnegie Mellon, Chicago, Columbia, Duke, Emory, Hong Kong University of Science and Technology, Illinois, London Business School, Maryland, Michigan, MIT, New York University, Rochester, Stanford, Texas-Austin, Toronto, University of California at Los Angeles, University of Southern California, Washington, and the 2007 WFA meetings for comments. All the remaining errors are my own. Research support from the Katherine Dusak Miller Ph.D. Fellowship in Finance is gratefully acknowledged. The views expressed herein are those of the author and do not necessarily reflect the views of the National Bureau of Economic Research.

NBER working papers are circulated for discussion and comment purposes. They have not been peerreviewed or been subject to the review by the NBER Board of Directors that accompanies official NBER publications.

(C) 2010 by Hui Chen. All rights reserved. Short sections of text, not to exceed two paragraphs, may be quoted without explicit permission provided that full credit, including $\odot$ notice, is given to the source. 
Macroeconomic Conditions and the Puzzles of Credit Spreads and Capital Structure

Hui Chen

NBER Working Paper No. 16151

July 2010

JEL No. E44,G12,G13,G32,G33

\begin{abstract}
$\underline{\text { ABSTRACT }}$
I build a dynamic capital structure model that demonstrates how business-cycle variations in expected growth rates, economic uncertainty, and risk premia influence firms' financing and default policies. Countercyclical fluctuations in risk prices, default probabilities, and default losses arise endogenously through firms' responses to the macroeconomic conditions. These comovements generate large credit risk premia for investment grade firms, which helps address the "credit spread puzzle" and "under-leverage puzzle" in a unified framework. The model generates interesting dynamics for financing and defaults, including "credit contagion" and market timing of debt issuance. It also provides a novel procedure to estimate state-dependent default losses.
\end{abstract}

Hui Chen

MIT Sloan School of Management

5 Cambridge Center, NE25-730

Cambridge, MA 02142

and NBER

huichen@mit.edu 
Risks associated with macroeconomic conditions are crucial for understanding asset prices. Naturally, they should also have important implications for corporate decisions. By introducing macroeconomic conditions into firms' financing decisions, this paper provides a risk-based explanation for two puzzles related to corporate debt. The first puzzle is the credit spread puzzle, where yield spreads between investment grade corporate bonds and Treasuries are high and volatile relative to the observed default rates and recovery rates. The second puzzle is the under-leverage puzzle, where firms choose low leverage ratios despite facing seemingly large tax benefits of debt and small costs of financial distress.

To address these puzzles, I build a structural model that endogenizes firms' financing and default decisions over the business cycle. In the model, aggregate consumption and firms' cash flows are exogenous. Firms' expected growth rates and volatility move slowly over time, which drives the business cycle. Asset prices are determined by a representative household with recursive preferences. The optimal capital structure is based on the trade-off between the tax benefits of debt and the deadweight losses of default. Examples of these deadweight losses include legal expenses and asset fire sale losses. Firms decide on how much debt to hold, when to restructure their debt, and when to default based on their cash flows as well as the macroeconomic conditions.

The main mechanism of the model is as follows. First, recessions are times of high marginal utilities, which means that default losses that occur during such times will affect investors more. Second, recessions are also times when firm cash flows are expected to grow more slowly, and to become both more volatile and more correlated with the market. These factors, combined with higher risk prices at such times, lower equity holders' continuation values, making defaults more likely in recessions. Third, since many firms experience poor performances in recessions, liquidating assets during such times can be particularly costly, which results in higher default losses. Taken together, the countercyclical variation in risk prices, default probabilities, and default losses raises the present value of expected default losses for bond holders and equity holders (who bear the deadweight losses ex ante), which leads to high credit spreads and low leverage ratios.

There are two types of shocks in this model: small shocks that directly affect the level of consumption and cash flows, and large shocks that change the conditional moments of growth rates over the business cycle. I model large shocks with a continuous-time Markov chain, which 
not only yields closed-form solutions for stock and bond prices, but also allows for analytical characterization of firms' default policies. Risk prices for small consumption shocks depend on the conditional volatility of consumption growth. Risk prices for large shocks depend on their frequency, size, and persistence. With recursive preferences, investors are concerned with news about future consumption. The arrival of a recession (a bad large shock) brings bad news of low expected growth rates and high economic uncertainty, which raises investors' marginal utilities. Thus, investors will demand a higher premium on securities that pay off poorly in such times.

To assess the quantitative performance of the model, a reasonable calibration is essential. The calibration strategy is to match the empirical moments of exogenous fundamentals. I use aggregate consumption and corporate profits data to calibrate consumption and the systematic components of firms' cash flows. The volatility of firm-specific shocks is calibrated to match the average default probabilities associated with firms' credit ratings. Preference parameters are calibrated to match moments from the asset market. Finally, default losses are estimated using the time series of aggregate recovery rates and the identification provided by the structural model. Relative to the case in which consumption and cash flow growth are i.i.d. and default losses are constant, the default component of the average 10-year Baa-Treasury spread in this model rises from 57 bps to $105 \mathrm{bps}$, while the average optimal market leverage of a Baa-rated firm drops from 50\% to 37\%, both consistent with the U.S. data.

Figure 1 provides some empirical evidence on the business cycle movements in default rates, credit spreads, and recovery rates. The dashed line in Panel A plots the annual default rates over 1920 to 2008. There are several spikes in the default rates, each coinciding with an NBER recession. The solid line plots the monthly Baa-Aaa credit spreads over 1920/01 to 2009/02. The spreads shoot up in most recessions, most visibly during the Great Depression, the S\&L crisis in the early 1980s, and the recent financial crisis in 2008. However, they do not always move in lock-step with default rates (the correlation at an annual frequency is 0.65), which suggests that other factors, such as recovery rates and risk premia, also affect the movements in spreads. Next, business cycle variation in the recovery rates is evident in Panel B. Recovery rates during the recessions in the sample, 1982, 1990, 2001, and 2008, are all below the sample average. ${ }^{1}$

Insert Figure 1 About Here 
A model that endogenizes capital structure decisions is well suited to address the credit spread and under-leverage puzzles for two reasons. First, it helps overcome the difficulty in estimating default probabilities (especially their time variation) for investment grade firms. By definition, these firms rarely default, which makes the model-generated spreads sensitive to small measurement errors in the conditional default probabilities. ${ }^{2}$ This model explicitly connects the conditional default probabilities to macroeconomic conditions and firm cash flows through firms' endogenous decisions, thus deriving more powerful predictions on the magnitude of the variation in the conditional default probabilities over the business cycle, as well as on how the conditional default probabilities comove with the risk premia.

The second advantage of a structural model is that it helps identify unobservable default losses for equity holders (deadweight losses) from observable bond recovery rates. In the model, recovery rates are determined by firm value at default net of default losses. Holding fixed the firm value at default, lower recovery rates imply higher default losses. Since the timing of default and firm value at default are endogenous, the model provides a precise link between recovery rates and default losses. Through this link, I estimate default losses and link them to the state of the economy.

To decompose the effects of business cycle risks on firms' financing decisions and the pricing of corporate securities, I examine several special cases of the model. First, I turn off the countercyclical variation in default losses and set it to its average value. The resulting leverage ratio is almost as high as in the case without business cycle risks, which implies that countercyclical default losses are crucial for generating low leverage ratios. Intuitively, firms are reluctant to take on leverage not because the deadweight losses of default are high on average, but because the losses are particularly high in those states in which defaults are more likely and losses are more painful.

Next, by shutting down the firm's exposure to systematic small shocks, I isolate the effects of the jump-risk premium (associated with the large and persistent business cycle shocks) on credit spreads and capital structure. In this case, the model generates 10 -year spreads that are 40 bps lower than in the full model but 36 bps higher than in a model without any systematic risk. The interest coverage also drops to half of its value in the full model, but is twice as high as in the case without business cycle risks. Hence, jump risks and Brownian risks are both important ingredients for the model. 
I also investigate how a high correlation of the firm's cash flows with the market affects capital structure and credit spreads. Holding systematic volatility fixed, I lower the firm's idiosyncratic volatility of cash flows (which causes the correlation with the market to rise) so that the firm's 10-year default probability drops to $0.6 \%$ (the 10-year default rate of Aaa-rated firms in the data). The firm's default risk becomes more systematic, that is, defaults are more concentrated in bad times, which generates sizable credit spreads despite the small default probability. However, even with high systematic risk, the firm still has much higher leverage compared to the Aaa firms in the data. This result suggests that a simple trade-off model such as the one considered here is unlikely to explain the low leverage of Aaa firms in the data.

The model has rich implications beyond credit spreads and leverage ratios. First, the model predicts that the covariation of firm cash flows with the market (both in levels and in conditional moments) will affect financing decisions, including leverage choice and the timing of default and restructuring under different macroeconomic conditions. For example, controlling for other factors, a firm with procyclical cash flows should have lower leverage (non-market-based) than one with countercyclical cash flows. It should also default earlier and restructure its debt upward less frequently.

Second, the model links the likelihood of default and upward debt restructuring to the expected growth rate and volatility of cash flows. Lower expected growth rates can make firms default sooner, but wait longer to issue additional debt. Higher volatility increases the option value of default and restructuring, which can make firms wait longer before exercising these options. One interesting prediction of the model is that upward restructuring probabilities will be more sensitive to changes in systematic volatility than default probabilities.

Third, with time variation in expected growth rates, volatility, and risk premia, there is no longer a one-to-one link between cash flows and market value of assets. An example of such delinkage is that the optimal default boundaries measured by cash flows are countercyclical, but they become procyclical if measured by asset value. It is important to consider such differences when we calibrate structural credit models with exogenous default boundaries.

Finally, the model generates contagion-like phenomena and market timing of debt issuance. The model generates default waves when the economy switches from a good state to a bad state. 
The same large shocks that cause a group of firms to default together also cause the credit spreads of other firms to jump up, a pattern that resembles credit contagion. On the flip side, when the economy enters into a good state, there is likely to be a wave of debt issuance (for healthy firms) at the same time when credit spreads jump down. These firms behave like market timers.

\section{Literature Review}

Huang and Huang (2003) summarize the credit spread puzzle. After calibrating a wide range of structural models to match the leverage ratios, default probabilities, and recovery rates of investment grade firms, they find that these models produce credit spreads well below historical averages. Miller (1977) highlights the under-leverage puzzle: the present value of expected default losses seems disproportionately small compared to the tax benefits of debt. Graham (2000) estimates the capitalized tax benefits of debt to be as high as $5 \%$ of firm value, much larger than conventional estimates for the value of expected default losses.

This paper is closely related to Hackbarth, Miao, and Morellec (2006), which is one of the first papers to show that macroeconomic conditions have rich implications for firms' financing policies. Their model assumes that investors are risk neutral, and focuses on the impact of macroeconomic conditions through the cash flow channel. In contrast, this paper emphasizes the effects of timevarying risk premia on firms' financing decisions and the pricing of corporate bonds.

Chen, Collin-Dufresne, and Goldstein (2009) apply a consumption-based asset pricing model to study the credit spread puzzle. They show that the strongly countercyclical risk prices generated by the habit formation model (Campbell and Cochrane (1999)), combined with exogenously imposed countercyclical asset value default boundaries, can generate high credit spreads. They do not study how macroeconomic conditions affect firms' financing and default decisions. Consistent with their insight, I show that in the long-run risk framework (Bansal and Yaron (2004), with time-varying expected growth rates and volatility), a dynamic trade-off model can endogenously generate the "right amount" of comovement in risk premia, default probabilities, and default losses, which explains the high credit spreads and low leverage ratios of investment grade firms.

A contemporaneous and independent paper by Bhamra, Kuehn, and Strebulaev (2009, BKS) uses a theoretical framework similar to this paper. While they focus on a unified model of the term structure of credit spreads and the levered equity premium, I focus on how business cycle 
risks affect firms' financing decisions. For calibration, BKS consider a two-state Markov chain and assume exogenous bankruptcy costs. I calibrate the model with nine states, which are able to capture richer dynamics of the business cycle and make it possible to separate the effects of time-varying expected growth rates from economic uncertainty. Moreover, I estimate firms' default losses via the structural model.

Almeida and Philippon (2007) use a reduced-form approach to study the connections between credit spreads and capital structure. They extract risk-adjusted default probabilities from observed credit spreads to calculate expected default losses and find values that are much larger than traditional estimates. Consistent with their finding, this paper shows that a structural model with macroeconomic risks can simultaneously match the credit spreads and leverage ratios. A new insight of this paper is that besides the risk-adjusted default probabilities, countercyclical default losses are also crucial for generating high ex ante default losses. ${ }^{3}$

The countercyclical default losses estimated in this paper can be motivated by Shleifer and Vishny (1992): asset liquidation is more costly in bad times because other firms in the economy are likely experiencing similar problems at such times. This is consistent with the empirical findings of Altman et al. (2005) and Acharya, Bharath, and Srinivasan (2007). The model's prediction that defaults depend on market conditions mirrors the finding of Pastor and Veronesi (2005) on IPO timing: just as new firms are more likely to "enter" the market (exercising the option to go public) in good times, existing firms are more likely to "exit" (via default) in bad times. The model's prediction that both cash flows and market value of assets help predict default probabilities is consistent with the empirical findings of Davydenko (2007).

The default risk premium in this model varies significantly over time, and has a large component due to jump risks (large and persistent macroeconomic shocks). These predictions are consistent with several recent empirical studies. In particular, Longstaff, Mithal, and Neis (2005) show that the majority of the corporate spreads are due to default risk, while Driessen (2005) and Berndt et al. (2008) estimate large jump-to-default risk premia in corporate bonds and credit default swaps. Berndt et al. (2008) also find dramatic time variation in credit risk premia.

This paper contributes to the long-run risk literature, led by Bansal and Yaron (2004) and Hansen, Heaton, and Li (2008), among others. It shows that the long-run risk model with time- 
varying volatility helps generate high credit spreads and low leverage ratios for firms. The Brownian motion-Markov chain setup in this paper gives closed-form solutions for the prices of stocks, bonds, and other claims without requiring the standard approximation techniques. This paper also provides a theoretical basis for using credit spreads to predict returns for stocks and bonds (Cochrane (2008) surveys these studies): unlike stocks, investment grade bonds are less sensitive to small cash flow shocks but more sensitive to fluctuations in aggregate risk, which makes the changes in their spreads a good proxy for the risk factors.

Finally, this paper provides a novel framework to bring macroeconomic conditions into dynamic capital structure models (see Brennan and Schwartz (1978), Fischer, Heinkel, and Zechner (1989), and Leland (1994, 1998), among others). Most of the existing models view default as an option for equity holders. Introducing business cycles increases the number of state variables, making the problem untractable. I approximate the dynamics of macro variables with a finite-state Markov chain, then apply the option pricing technique of Jobert and Rogers (2006). This method reduces a high-dimensional free-boundary problem into a system of ODEs with closed-form solutions.

The paper is organized as follows. Section I describes the economy and the setup of the firm's problem. Section II discusses the dynamic financing decisions. Section III calibrates the model and analyzes the results. Section IV concludes.

\section{The Economy}

Consider an economy with a government, firms, and households. The government serves as a tax authority, levying taxes on corporate profits, dividends, and interest income. Firms are financed by debt and equity. Households both own and lend to firms. Below I first introduce the macroeconomic environment, including preferences and technology, which determines how aggregate risks and risk prices change with the business cycle. I then describe firms' financing, restructuring, and default decisions. 


\section{A. Preferences and Technology}

There are a large number of identical infinitely lived households in the economy. The representative household has stochastic differential utility of Duffie and Epstein (1992a, 1992b), which is a continuous-time version of the recursive preferences of Kreps and Porteus (1978), Epstein and Zin (1989), and Weil (1990). I define the utility index over a consumption process $c$ as

$$
U_{t}=E_{t}\left(\int_{t}^{\infty} f\left(c_{s}, U_{s}\right) d s\right)
$$

The function $f(c, v)$ is a normalized aggregator of consumption and continuation value in each period, and is defined as

$$
f(c, v)=\frac{\rho}{1-\frac{1}{\psi}} \frac{c^{1-\frac{1}{\psi}}-((1-\gamma) v)^{\frac{1-1 / \psi}{1-\gamma}}}{((1-\gamma) v)^{\frac{1-1 / \psi}{1-\gamma}-1}}
$$

where $\rho$ is the rate of time preference, $\gamma$ determines the coefficient of relative risk aversion for timeless gambles, and $\psi$ determines the elasticity of intertemporal substitution for deterministic consumption paths.

There are two types of shocks that affect real output in this economy: small shocks that directly affect the level of output, and large but infrequent shocks that change the expected growth rate and volatility of output. Specifically, a standard Brownian motion $W_{t}^{m}$ provides small systematic shocks to the real economy. Large shocks come from movements in a state variable $s_{t}$. I assume that $s_{t}$ follows an $n$-state time-homogeneous Markov chain, and takes values in the set $\{1, \cdots, n\}$. The generator matrix for the Markov chain is $\boldsymbol{\Lambda}=\left[\lambda_{j k}\right]$ for $j, k \in\{1, \cdots, n\}$. Simply put, the probability of $s_{t}$ moving from state $j$ to $k$ within time $\Delta$ is approximately $\lambda_{j k} \Delta$.

We can equivalently express this Markov chain as a sum of Poisson processes,

$$
d s_{t}=\sum_{k \neq s_{t^{-}}} \delta_{k}\left(s_{t^{-}}\right) d N_{t}^{\left(s_{t^{-}}, k\right)}
$$

where

$$
\delta_{k}(j)=k-j,
$$


and $N_{t}^{(j, k)}(j \neq k)$ are independent Poisson processes with intensity parameters $\lambda_{j k}$. Each jump in $s_{t}$ corresponds to a change of state for the Markov chain.

Let $Y_{t}$ be the real aggregate output in the economy at time $t$, which follows the process

$$
\frac{d Y_{t}}{Y_{t}}=\theta_{m}\left(s_{t}\right) d t+\sigma_{m}\left(s_{t}\right) d W_{t}^{m}
$$

The state variable $s_{t}$ determines $\theta_{m}$ and $\sigma_{m}$, the expected growth rate and volatility of aggregate output, respectively. With a sufficiently large $n$, equation (4) can capture rich dynamics in $\theta_{m}$ and $\sigma_{m}$. Thus, this model of output can be used as a discrete-state approximation of the consumption model in Bansal and Yaron (2004), where they interpret the volatility of consumption/output growth as a measure of economic uncertainty. The fluctuations in the expected growth rate of aggregate output and economic uncertainty generate the business cycles in this model.

In equilibrium, aggregate consumption equals aggregate output, which determines the stochastic discount factor as follows.

PROPOSITION 1: The real stochastic discount factor follows a Markov-modulated jump-diffusion,

$$
\frac{d m_{t}}{m_{t}}=-r\left(s_{t}\right) d t-\eta\left(s_{t}\right) d W_{t}^{m}+\sum_{s_{t} \neq s_{t^{-}}}\left(e^{\kappa\left(s_{t^{-}}, s_{t}\right)}-1\right) d M_{t}^{\left(s_{t^{-}}, s_{t}\right)}
$$

where $r$ is the real risk-free rate, $\eta$ is the risk price for systematic Brownian shocks $W_{t}^{m}$,

$$
\eta\left(s_{t}\right)=\gamma \sigma_{m}\left(s_{t}\right)
$$

$\kappa(j, k)$ is the relative jump size of the discount factor when the Markov chain switches from state $j$ to $k$, and $M_{t}$ is a matrix of compensated processes,

$$
d M_{t}^{(j, k)}=d N_{t}^{(j, k)}-\lambda_{j k} d t, \quad j \neq k,
$$

where $N_{t}^{(j, k)}$ are the Poisson processes in (3). The expressions $r$ and $\kappa$ are given in Appendix $A$.

The stochastic discount factor is driven by the same set of shocks that drives aggregate output. Small systematic shocks affect marginal utility through today's consumption levels. The risk price 
for these shocks $\left(\eta\left(s_{t}\right)\right)$ rises with risk aversion and local consumption volatility. Large shocks change the state of the economy and cause jumps in the discount factor, even though consumption does not have jumps. The relative jump sizes $\kappa(j, k)$ of the stochastic discount factor are the risk prices for these shocks.

Changes in the state of the economy cause jumps in the discount factor due to recursive preferences. With such preferences, investors care about the temporal distribution of risk. Their marginal utility depends not only on current consumption, but also on news about future consumption. For example, when a recession arrives (caused by a jump in the state $s_{t}$ ), it brings the bad news of low expected growth rates and high economic uncertainty. Marginal utility then rises, resulting in a jump in the discount factor. With time-separable preferences, investors would be indifferent to the temporal distribution of risk, in which case these large shocks would no longer have immediate effects on the discount factor.

Since credit spreads are based on nominal yields and taxes are collected on nominal cash flows, I specify a simple stochastic consumption price index $P_{t}$ to get nominal prices:

$$
\frac{d P_{t}}{P_{t}}=\pi d t+\sigma_{P, 1} d W_{t}^{m}+\sigma_{P, 2} d W_{t}^{P}
$$

where $W_{t}^{P}$ is a Brownian motion independent of $W_{t}^{m}$. For simplicity, I assume that the expected inflation rate $\pi$ and volatility $\left(\sigma_{P, 1}, \sigma_{P, 2}\right)$ are constant. It follows that the nominal stochastic discount factor is $n_{t}=m_{t} / P_{t}$, and the nominal interest rate is

$$
r^{n}\left(s_{t}\right)=r\left(s_{t}\right)+\pi-\sigma_{P}^{2}-\sigma_{P, 1} \eta\left(s_{t}\right)
$$

which is the sum of the real interest rate, expected inflation, and the inflation risk premium.

\section{B. Firms}

Each firm in the economy has a technology that produces a perpetual stream of cash flows. Let $Y_{f, t}$ be the real cash flows of firm $f$, which follows the process

$$
\frac{d Y_{f, t}}{Y_{f, t}}=\theta_{f}\left(s_{t}\right) d t+\sigma_{f, m}\left(s_{t}\right) d W_{t}^{m}+\sigma_{f} d W_{t}^{f}
$$


where $\theta_{f}\left(s_{t}\right)$ and $\sigma_{f, m}\left(s_{t}\right)$ are the firm's expected growth rate and systematic volatility of cash flows in state $s_{t}, W_{t}^{f}$ is an independent standard Brownian motion that generates idiosyncratic shocks specific to the firm, and $\sigma_{f}$ is the firm's idiosyncratic volatility, which is constant over time. Since operating expenses such as wages are not included in the earnings but are still part of aggregate output, the earnings across all firms do not add up to aggregate output $Y_{t}$.

To link the systematic components of firm cash flows to aggregate output, I make the following assumptions:

$$
\begin{gathered}
\theta_{f}\left(s_{t}\right)=a_{f}\left(\theta_{m}\left(s_{t}\right)-\bar{\theta}_{m}\right)+\bar{\theta}_{f}, \\
\sigma_{f, m}\left(s_{t}\right)=b_{f}\left(\sigma_{m}\left(s_{t}\right)-\bar{\sigma}_{m}\right)+\bar{\sigma}_{f, m},
\end{gathered}
$$

where $\bar{\theta}_{m}$ and $\bar{\sigma}_{m}$ are the long-run mean and long-run volatility of the growth rate of aggregate output, while $\bar{\theta}_{f}$ and $\bar{\sigma}_{f, m}$ are the long-run mean and long-run systematic volatility of the firm's growth rate. The coefficients $a_{f}$ and $b_{f}$ determine the sensitivity of the firm-level expected growth rate and systematic volatility to variation in the aggregate growth rate and volatility. Equation (12) also implies time-varying correlation between firm cash flows and aggregate output (market). The correlation will be higher at times when the systematic volatility of output $\sigma_{m}\left(s_{t}\right)$ is high.

The nominal cash flow of the firm above is $X_{t}=Y_{f, t} P_{t}$. Applying Ito's formula gives

$$
\frac{d X_{t}}{X_{t}}=\theta_{X}\left(s_{t}\right) d t+\sigma_{X, m}\left(s_{t}\right) d W_{t}^{m}+\sigma_{P, 2} d W_{t}^{P}+\sigma_{f} d W_{t}^{f}
$$

where

$$
\begin{aligned}
\theta_{X}\left(s_{t}\right) & =\theta_{f}\left(s_{t}\right)+\pi+\sigma_{f, m}\left(s_{t}\right) \sigma_{P, 1}, \\
\sigma_{X, m}\left(s_{t}\right) & =\sigma_{f, m}\left(s_{t}\right)+\sigma_{P, 1} .
\end{aligned}
$$

To price assets in this economy, we can discount cash flows with the risk-free rate under the riskneutral probability measure $\mathcal{Q}$. Intuitively, the risk-neutral measure adjusts for risks by changing the distributions of shocks. Under $\mathcal{Q}$, the expected growth rate of the firm's nominal cash flows 
becomes

$$
\tilde{\theta}_{X}\left(s_{t}\right)=\theta_{X}\left(s_{t}\right)-\sigma_{X, m}\left(s_{t}\right)\left(\eta\left(s_{t}\right)+\sigma_{P, 1}\right)-\sigma_{P, 2}^{2} .
$$

Cash flows are risky when they are positively correlated with marginal utility $\left(\sigma_{X, m}\left(s_{t}\right)>0\right)$, which is accounted for by a lower expected growth rate under $\mathcal{Q}$.

In addition, the generator matrix for the Markov chain becomes $\tilde{\boldsymbol{\Lambda}}=\left[\tilde{\lambda}_{j k}\right]$, where the transition intensities are adjusted by the size of the corresponding jumps in the stochastic discount factor $\kappa(j, k)$ (see equation $(5))$ :

$$
\begin{aligned}
& \tilde{\lambda}_{j k}=e^{\kappa(j, k)} \lambda_{j k}, \quad j \neq k \\
& \tilde{\lambda}_{j j}=-\sum_{k \neq j} \tilde{\lambda}_{j k} .
\end{aligned}
$$

The factor $e^{\kappa(j, k)}$ is the jump-risk premium associated with the shock that moves the economy from state $j$ to $k$. Intuitively, bad news about future cash flows is particularly "painful" if it occurs when the economy enters into a recession (marginal utility jumps up). The risk-neutral measure adjusts for such risks by raising the probability that the economy will enter into a bad state and lowering the probability that it will leave a bad state. For example, if marginal utility doubles when the economy changes from state $j$ to $k$, that is, $e^{\kappa(j, k)}=2$, then the jump intensity associated with this change of state will be twice as high under the risk-neutral measure.

For a firm that never takes on leverage, its value is the present value of its cash flow stream. Given the current cash flow $X_{t}$ and the state of the economy $s_{t}$, the value of the unlevered firm (before taxes) is

$$
V\left(X_{t}, s_{t}\right)=X_{t} v\left(s_{t}\right)
$$

where the price-earnings ratio $v\left(s_{t}\right)$ is given by a vector $\mathbf{v}=[v(1), \ldots, v(n)]^{\prime}$,

$$
\mathbf{v}=\left(\mathbf{r}^{n}-\tilde{\theta}_{X}-\tilde{\Lambda}\right)^{-1} \mathbf{1}
$$

The expression $\mathbf{r}^{n}$ is an $n \times n$ diagonal matrix with its $i$-th diagonal element given by $r^{n}(i)$, the nominal interest rate in state $i$; similarly, $\tilde{\theta}_{X}$ is an $n \times n$ diagonal matrix with its $i$-th diagonal element given by $\tilde{\theta}_{X}(i)$, the firm's risk-neutral expected growth rate in state $i$ (see equation (16)). 
The vector $\mathbf{1}$ is an $n \times 1$ vector of ones, and $\tilde{\boldsymbol{\Lambda}}$ is the generator of the Markov chain under the risk-neutral measure (see equation (17)).

Equation (19) is the generalized Gordon growth formula. If there are no large shocks, the priceearnings ratio will be constant, $v=1 /\left(r^{n}-\tilde{\theta}\right)$, where $\tilde{\theta}$ is the constant expected growth rate under the risk-neutral measure. The new feature in this model is that the expected growth rate is adjusted

by $\tilde{\boldsymbol{\Lambda}}$, the risk-neutral Markov chain generator, which accounts for possible changes of state in the future. Equation (19) implies procyclical variation in the price-earnings ratio. Bad times come with higher risk prices, higher systematic cash flow volatility, and lower expected growth rate, all of which lead to a smaller risk-neutral growth rate and tend to lower the firm value for a given cash flow. Moreover, the risk-neutral transition probabilities increase the duration of bad times, which pushes down the firm value in the bad states further.

Next, we can view a default-free consol bond as an asset whose cash flow stream has zero growth rate and volatility. It immediately follows from equations (18) and (19) that, in state $s$, the value of the default-free consol with coupon rate $C$ (before taxes) is

$$
B(C, s)=C b(s)
$$

where

$$
\mathbf{b}=[b(1), \cdots, b(n)]^{\prime}=\left(\mathbf{r}^{n}-\tilde{\mathbf{\Lambda}}\right)^{-1} \mathbf{1} .
$$

\section{Financing and Default}

The setup of firms' financing problems follows that of Goldstein, Ju, and Leland (2001) and Hackbarth, Miao, and Morellec (2006). Firms make financing and default decisions with the objective of maximizing equity holders' value. Since interest expenses are tax deductible, firms lever up with debt to exploit the tax shield. As the amount of debt increases, so does the probability of default, which raises the expected default losses. Thus, firms will lever up to a point where the net marginal benefit of debt is zero.

Firms have access to two types of external financing: debt and equity. I assume that firms do not hold cash reserves. In each period, a levered firm first uses its cash flow to make interest 
payments, then pays taxes, and then distributes the rest to equity holders as dividends. When internally generated cash cannot cover the firm's interest expenses, the firm may be able to issue equity to cover the shortfall, which intuitively can also be viewed as a form of "super junior" perpetual debt. If equity holders are no longer willing to inject more capital, the firm defaults.

Debt is modeled as a consol bond, that is, a perpetuity with constant coupon rate $C$. This is a standard assumption in the literature (see for example, Leland (1994), Duffie and Lando (2001)), which helps maintain a time-homogeneous setting. I assume that debt is issued and callable at par. Issuing debt incurs a cost that is a constant fraction $q$ of the amount of issuance. Following Goldstein, Ju, and Leland (2001), I assume that when restructuring its debt, the firm first calls all the outstanding debt and then issues new debt. This assumption helps simplify the seniority structure of the outstanding debt, and introduces lumpiness in debt issuance, which is consistent with firms' financing behavior in practice. ${ }^{4}$

For tractability reasons, I assume that firms can only adjust debt levels upward. In reality, firms in financial distress can reduce their debt by selling part of their assets or entering debt-for-equity swaps. However, Asquith, Gertner, and Scharfstein (1997) find that asset fire sale losses, free-rider problems, and other regulations make such restructurings costly. Gilson (1997) shows that because of the high transaction costs, leverage of financially distressed firms remains high before Chapter 11. These evidence suggest that introducing downward restructuring is unlikely to substantially change the results. I discuss the potential impacts of downward restructuring in Section III.D.

At the time of default, the absolute priority rule applies. Specifically, equity holders receive nothing at default, while debt holders recover a fraction $\alpha$ of the firm's unlevered assets. ${ }^{5}$ For the firm, the default losses are the difference between the value of the levered firm and the recovery value of debt. To allow these dead-weight losses to vary with economic conditions, I model the firm recovery rate $\alpha(s)$ as a function of the state of the economy.

Finally, the tax environment consists of a constant tax rate $\tau_{i}$ for personal interest income, $\tau_{d}$ for dividend income, and $\tau_{c}$ for corporate earnings. A constant $\tau_{c}$ implies that the firm will not lose its tax shield when there are net operating losses. Chen (2007) investigates the effects of partial loss offset by lowering the corporate tax rate when the firm's taxable income is negative. In that case, tax benefits become procyclical, which lowers the expected tax benefit of debt, and the firm 
will choose a lower leverage.

\section{C.1. Firm's Problem}

The firm acts in the interest of its equity holders. At $t=0$ as well as at each restructuring point, the firm chooses the amount of debt and the time to restructure $\mathcal{T}_{U}$ to maximize the value of equity right before issuance, ${ }^{6} E_{U}$, which in turn is equal to the expected present value of firm cash flows, plus the tax benefits of debt, minus the default losses and debt issuance costs. After debt is issued or restructured, the firm chooses the time to default $\mathcal{T}_{D}$ to maximize the value of equity.

Having set up the model, I next discuss how to solve for the optimal financing, restructuring, and default decisions.

\section{Dynamic Financing Decisions}

At $t=0$, the economy is in state $s_{0}$. Without loss of generality, I normalize the initial cash flow $X_{0}=1$. The coupon that the firm chooses at $t=0$ depends on the initial state, and is denoted as $C\left(s_{0}\right)$. The decisions on when to restructure the firm's debt and when to default depend on the initial coupon, and hence depend indirectly on the initial state $s_{0}$.

The default policy is determined by a set of default boundaries $\left\{X_{D}^{1}\left(s_{0}\right), \ldots, X_{D}^{n}\left(s_{0}\right)\right\}$. The firm defaults if its cash flow is below the boundary $X_{D}^{k}\left(s_{0}\right)$ while the economy is in state $k$. Similarly, the restructuring policy is determined by a set of upward restructuring boundaries $\left\{X_{U}^{1}\left(s_{0}\right), \ldots, X_{U}^{n}\left(s_{0}\right)\right\}$ and the corresponding new coupon rates. The firm restructures whenever its cash flow is above the boundary $X_{U}^{k}\left(s_{0}\right)$ while the economy is in state $k$.

One can always re-order the states such that

$$
X_{D}^{1}\left(s_{0}\right) \leq X_{D}^{2}\left(s_{0}\right) \leq \cdots \leq X_{D}^{n}\left(s_{0}\right)
$$

However, there is no guarantee that the restructuring boundaries will have the same ordering. To accommodate potentially different orderings, I define function $u(\cdot)$ that maps the (endogenous) order of restructuring boundaries across states into the indices for the states. For example, $u(i)$ 
denotes the state with the $i$-th lowest restructuring boundary. Then, by definition,

$$
X_{U}^{u(1)}\left(s_{0}\right) \leq X_{U}^{u(2)}\left(s_{0}\right) \leq \cdots \leq X_{U}^{u(n)}\left(s_{0}\right)
$$

For reasonable parameters, the default and restructuring boundaries are sufficiently apart such that $X_{D}^{n}\left(s_{0}\right)<X_{0}<X_{U}^{u(1)}\left(s_{0}\right)$.

To facilitate notation, I divide the relevant range for cash flow into $2 n-1$ regions. First, there are $n-1$ default regions, defined as $\mathcal{D}_{k}=\left[X_{D}^{k}\left(s_{0}\right), X_{D}^{k+1}\left(s_{0}\right)\right)$ for $k=1, \cdots, n-1$. When the firm's cash flow is in one of these regions, the firm faces immediate default threat. For example, suppose the economy is currently in state 1 , which has the lowest default boundary. If cash flow is in region $\mathcal{D}_{n-1}$, then it is below the default boundary in state $n$, but above the boundary for the current state. The firm will not default now, but if the state suddenly changes from 1 to $n$, it will default immediately. Next, in region $\mathcal{D}_{n}=\left[X_{D}^{n}\left(s_{0}\right), X_{U}^{u(1)}\left(s_{0}\right)\right)$, the firm will not immediately default or restructure. Finally, there are $n-1$ restructuring regions, $\mathcal{D}_{n+k}=\left(X_{U}^{u(k)}\left(s_{0}\right), X_{U}^{u(k+1)}\left(s_{0}\right)\right]$ for $k=1, \cdots, n-1$, where a change of state can trigger immediate restructuring.

I solve the financing problem in three steps. First, for a given amount of debt outstanding and a set of default/restructuring boundaries, I provide closed-form solutions for the value of debt and equity. Second, the optimal default boundaries for a given coupon and a set of restructuring boundaries are determined by the smooth-pasting conditions in each state. Third, I solve for the optimal amount of debt and restructuring boundaries by maximizing the value of equity before debt issuance subject to the smooth-pasting conditions for the default boundaries.

\section{A. Scaling Property}

Thanks to the homogeneity of the problem, the dynamic capital structure model can be reduced to a static problem using the scaling property. The scaling property states that, conditional on the state of the economy, the optimal coupon, the default and restructuring boundaries, and the value of debt and equity at the restructuring points are all homogeneous of degree one in cash flow. This is a generalized version of the scaling property used by Goldstein, Ju, and Leland (2001). The intuition is as follows. If the state is the same, the firm at two adjacent restructuring points faces 
an identical problem, except that the cash flow levels are different. The log-normality of cash flows and proportional costs of debt issuance guarantee that if the cash flow has doubled, it is optimal to double the amount of debt and the default/restructuring boundaries, and the value of debt and equity will double as well.

The scaling property only holds after conditioning on the state. The following example illustrates how we can apply scaling when the state changes. Suppose the economy is in state 1 at time 0 , and a firm chooses coupon $C(1)$ and default/restructuring boundaries given this initial state. The rest of the states can be viewed as "shadow states," which also have their own optimal coupon $C(s)$ and default/restructuring boundaries. Next, suppose the firm decides to restructure at time $t$ in state 2 , with cash flow $X_{t}$. Then the scaling factor is $X_{t} / X_{0}$, which should be applied to $C(2)$, the "shadow coupon" in state 2 at time 0 , as opposed to $C(1)$, to get the correct new coupon rate.

Next, I discuss how to price debt and equity, and solve for the optimal policies.

\section{B. Debt and Equity}

Both debt and equity can be viewed as a contingent claim that pays "dividend" $F\left(X_{t}, s_{t}\right)$ until default or upward restructuring occurs, whichever comes first; it makes a final payment of $H\left(X_{\mathcal{T}_{D}}, s_{\mathcal{T}_{D}}\right)$ upon default, and of $K\left(X_{\mathcal{T}_{U}}, s_{\mathcal{T}_{U}}\right)$ upon restructuring. I specify the value of dividend $F$, default payment $H$, and restructuring payment $K$ for debt and equity in Appendix B.

For a given initial state $s_{0}$, coupon rate, and default/restructuring boundaries, the value of debt $D\left(X, s ; s_{0}\right)$ and equity $E\left(X, s ; s_{0}\right)$ can be solved analytically. Proposition 2 in Appendix B summarizes the formulas. Next, for each initial state $s_{0}$, the default boundaries satisfy the smoothpasting conditions in each of the $n$ states:

$$
\left.\frac{\partial}{\partial X} E\left(X, k ; s_{0}\right)\right|_{X \downarrow X_{D}^{k}\left(s_{0}\right)}=0, \quad k=1, \ldots, n .
$$

Since $E\left(X, k ; s_{0}\right)$ is known in closed form, these smooth-pasting conditions translate into a system of nonlinear equations, which is solved numerically.

Default can be triggered by small shocks or large shocks. In the case of small shocks, the state of the economy does not change, but a series of small negative shocks drives the cash flow below the 
default boundary in the current state. Alternatively, the cash flow can still be above the current boundary, but a sudden change of state (from good to bad) causes the default boundary to jump above the cash flow, leading the firm to default immediately. Importantly, this means that the cash flow at default might not be equal to any of the default boundaries. Figure 2 illustrates these two types of default.

\section{Insert Figure 2 About Here}

The second type of default generates default waves: firms with cash flows between two default boundaries can default at the same time when a large shock arrives. The model of Hackbarth, Miao, and Morellec (2006, HMM) generates a similar feature, but with a very different mechanism. In HMM, default waves occur when aggregate cash flow levels jump down; here, default waves are caused by large changes in the expected growth rate, volatility, and/or risk prices. To test these models, we can check empirically whether default waves coincide with significant drops in aggregate output (according to HMM), or whether they forecast a low growth rate and/or high volatility of aggregate output/cash flows in the future (this model). The restructuring boundaries have similar properties. A sudden change of state (from bad to good) can cause the restructuring boundary to jump down, which generates debt issuance waves.

The value of equity immediately before levering up is equal to the sum of the value of debt and equity after issuance, net of issuance costs (a fraction $q$ of the amount of debt issued),

$$
E_{U}\left(X_{0}, s_{0}\right)=(1-q) D\left(X_{0}, s_{0} ; s_{0}\right)+E\left(X_{0}, s_{0} ; s_{0}\right)
$$

The optimal financing policy includes the optimal coupon rate $C\left(s_{0}\right)$ and the corresponding restructuring boundaries $\mathbf{X}_{U}\left(s_{0}\right)=\left\{X_{U}^{1}\left(s_{0}\right), \ldots, X_{U}^{n}\left(s_{0}\right)\right\}$ and default boundaries $\mathbf{X}_{D}\left(s_{0}\right)=$ $\left\{X_{D}^{1}\left(s_{0}\right), \ldots, X_{D}^{n}\left(s_{0}\right)\right\}$ for each initial state $s_{0}$. Due to the homogeneity of the problem, the optimal default and restructuring boundaries corresponding to each initial state will be proportional to the coupon chosen for that state, that is,

$$
\frac{X_{D}^{k}(j)}{X_{D}^{k}(i)}=\frac{X_{U}^{k}(j)}{X_{U}^{k}(i)}=\frac{C(j)}{C(i)}, \quad i, j, k=1, \cdots, n
$$


Using this property, we only need to search for the optimal coupons $\{C(1), \ldots, C(n)\}$ and the optimal restructuring $\mathbf{X}_{U}\left(s_{0}\right)=\left\{X_{U}^{1}\left(s_{0}\right), \ldots, X_{U}^{n}\left(s_{0}\right)\right\}$ to maximize the value of equity before levering up in one initial state, subject to the smooth-pasting conditions for the default boundaries (22),

$$
\left(C^{*}(1), \cdots, C^{*}(n), \mathbf{X}_{U}(1)\right)=\underset{C(1), \cdots, C(n), \mathbf{X}_{U}(1)}{\operatorname{argmax}} E_{U}\left(X_{0}, s_{0} ; C(1), \cdots, C(n)\right) .
$$

\section{Results}

I now turn to the quantitative performance of the model. I first calibrate the model parameters using data on aggregate consumption, corporate profits, moments of the asset market, firm default rates, and bond recovery rates. Next, I calculate the optimal leverage ratio and credit spreads, as well as other financing policy variables. Since the credit spreads of the consols in the model are not directly comparable with those of finite maturity bonds, I also compute the spreads of hypothetical 10-year coupon bonds with the same default timings and recovery rates as the consols.

As Huang and Huang (2003) show, the main challenge of the credit spread puzzle is to explain the spreads between investment grade bonds (Baa and above) and Treasury bonds. There are very few Aaa-rated nonfinancial firms in the data, and they tend to have very low leverage that is unlikely to be explained by the trade-off between tax benefits and costs of financial distress alone. Thus, I focus the analysis mainly on Baa-rated firms.

Duffee (1998) reports that the average credit spread between a Baa-rated 10-year bond in the industrial sector and the Treasury is 148 bps, while the Aaa-Treasury spread is 47 bps. Many studies argue that liquidity and taxes account for part of these credit spreads, which are not modeled in this paper. It is important to correct for these non-default components in the spreads, because otherwise the model that matches these spreads would generate credit risk premia that are too large, and the leverage ratio would be biased downward. Longstaff, Mithal, and Neis (2005) estimate that the default component accounts for $51 \%$ of the spread for AAA-rated bonds and $71 \%$ for BBB-rated bonds. Assuming that the S\&P BBB (AAA) ratings are comparable to the Baa (Aaa) ratings of Moody's, I set the target spread of a 10-year Baa-rated bond to 105 bps, which is actually quite close to the average Baa-Aaa spread (101 bps). Almeida and Philippon (2007) make 
a similar adjustment to credit spreads when computing risk-neutral default probabilities.

For the leverage ratio, Chen, Collin-Dufresne, and Goldstein (2009) estimate the average market leverage for Baa firms to be $44 \%$. However, since a model can potentially misprice debt and/or equity, it might be more appropriate to use non-market-based measures of leverage to compare results across models, such as the interest coverage (EBIT over interest expenses). In the data the median interest coverage for BBB-rated firms is around four.

\section{A. Calibration}

I calibrate the Markov chain that controls the conditional moments of consumption growth based on the long-run risk model of Bansal and Yaron (2004), which is in turn calibrated to annual consumption data from 1929 to 1998. Appendix C provides the details of this calibration. I choose nine states for the Markov chain (Table A.I reports the values of these states), which maintains the tractability of the model while allowing for more realistic dynamics in the conditional moments of consumption than a two-state model. ${ }^{7}$ Simulations show that the Markov chain captures the main properties of consumption well. Some of the median statistics from simulations (with empirical estimates reported in parentheses for comparison) are: average annual growth rate $1.81 \%$ (1.80\%), volatility $2.64 \%(2.93 \%)$, first-order autocorrelation 0.42 (0.49), and second-order autocorrelation 0.18 (0.15). Panel A of Figure 3 plots the stationary distribution of the Markov chain. In the long run, the economy is in the state with medium growth rate and volatility (state 5) $54 \%$ of the time.

\section{Insert Figure 3 About Here}

Table I summarizes the asset pricing implications of the Markov chain model. The equity premium is computed for a levered-up dividend claim as in Bansal and Yaron (2004). With preference parameters $\gamma=7.5, \psi=1.5$, and $\rho=0.015$, the model generates moments for asset prices that are consistent with the data. The model predicts that the real risk-free rate is procyclical, that is, higher in times of high expected growth (Panel B of Figure 3), and that the real yield curve is downward sloping on average. These results are consistent with the empirical findings of Chapman (1997) and the model of Piazzesi and Schneider (2006). The model also generates a sizable jumprisk premium associated with the Markov chain (defined in (17)), as shown in Panel C. For example, 
the risk-neutral probability of switching from the medium state (state 5) to the worst state (state 9, with low growth and high volatility) is about 2.5 times as high as its actual probability.

\section{Insert Table I About Here}

To calibrate the cash flow process for a Baa-rated firm, I fix the long-run average growth rate of a firm's cash flows $\bar{\theta}_{f}$ to be the same as that of aggregate consumption. I then calibrate the coefficients $a_{f}, b_{f}$, and the average systematic volatility $\bar{\sigma}_{f, m}$ to fit the moments of the time series of corporate profits for nonfinancial firms (from NIPA). The idiosyncratic volatility $\sigma_{f}$ is estimated jointly with the firm recovery rate $\alpha\left(s_{t}\right)$ to match the moments of recovery rates and the 10-year cumulative default probability of Baa-rated firms. I discuss the details of this estimation later.

I use the tax rate estimates of Graham (2000), which take into account the fact that the tax benefits of debt at the corporate level are partially offset by individual tax disadvantages of interest income. Inflation parameters are calibrated using the price index for nondurables and services from NIPA. The costs of debt issuance are from Altinkilic and Hansen (2000). Table II summarizes the calibrated parameters.

\section{Insert Table II About Here}

\section{A.1. Estimating State-dependent Default Losses}

There are direct and indirect costs for firms going through financial distress. Examples of direct costs include legal expenses and losses due to asset fire sales. Examples of indirect costs include debt overhang (Myers (1977)), asset substitution (Jensen and Meckling (1976)), as well as losses of human capital.

In a model with business cycles, it is crucial to recognize that not just the average level of default losses, but also the distribution of default losses over different states of the economy matter for capital structure and credit spreads. Shleifer and Vishny (1992) argue that liquidation of assets will be particularly costly when many firms are in distress, which implies that default losses are likely to be countercyclical. However, default losses are difficult to measure, because it is difficult to distinguish between losses due to financial and economic distress (see Andrade and Kaplan (1998)). 
Instead, most structural models assume default losses to be a constant fraction of the value of assets at default.

I use a new approach to estimate default losses. In this model, the recovery value of corporate bonds is equal to firm value at default net of default losses. Unlike default losses, bond recovery rates are observable, and have a relatively long time series (Moody's aggregate recovery rate series spans 1982 to 2008). Since the model endogenously determines the default boundaries (hence the firm's value at default), we can back out the implied default losses for any given recovery rate. Thus, this structural model makes it possible to identify the time variation in default losses from the variation in bond recovery rates.

Specifically, I model the firm's recovery rate $\alpha\left(s_{t}\right)$ as a function of the expected growth rate $\theta_{m}\left(s_{t}\right)$ and volatility $\sigma_{m}\left(s_{t}\right)$ of aggregate output,

$$
\alpha\left(s_{t}\right)=a_{0}+a_{1} \theta_{m}\left(s_{t}\right)+a_{2} \theta_{m}^{2}\left(s_{t}\right)+a_{3} \sigma_{m}\left(s_{t}\right) .
$$

The quadratic term in (26) allows $\alpha$ to be increasing and concave in the expected growth rate, which is consistent with the data (the Internet Appendix provides empirical evidence supporting this specification). In the estimation, I impose the constraint that $\alpha\left(s_{t}\right)$ is increasing in $\theta_{m}\left(s_{t}\right)$ (holding $\sigma_{m}\left(s_{t}\right)$ fixed).

I estimate the coefficients for $\alpha\left(s_{t}\right)$ and the idiosyncratic volatility of cash flows $\sigma_{f}$ jointly using simulated method of moments (SMM). The model's predicted moments are computed by simulating a cohort of 1,000 firms (with the same cash flow parameters but experiencing different idiosyncratic shocks) for 100 years. Panel A of Table III reports the target moments. The average bond recovery rate is $41.4 \%$. The recovery rates are strongly negatively correlated with default rates (with a correlation of -0.82), and are positively correlated with the growth rates of corporate profits (with a correlation of 0.58$)$. Panel $\mathrm{B}$ reports the estimation results. The values for the recovery rate $\alpha$ from the estimation are plotted in Panel D of Figure 3. For most states, the value of $\alpha$ is around 0.6. For those states in which the expected growth rate is low, the recovery rate drops significantly, particularly in the state with high economic uncertainty.

Insert Table III About Here 
How does the model identify countercyclical default losses? While asset values tend to drop in recessions because of lower price-earnings ratios, they do not drop as much as bond recovery rates. Moreover, firms tend to default at higher cash flow levels in recessions, which further reduces the variation in firm value at default. Default losses must therefore be higher in recessions in order for the model to fit the low recovery rates at those times. The average default losses implied by the estimates of $\alpha$ are about $2 \%$ of initial firm value, which is reasonable compared to the estimates of Andrade and Kaplan (1998).

\section{B. Capital Structure and Credit Spreads}

To illustrate the difficulty that standard structural models have in generating reasonable credit spreads and leverage ratios, I first study a special case of the model by shutting down business cycle risks. The expected growth rate and systematic volatility of cash flows are fixed at their unconditional means. The stochastic discount factor in equation (5) is replaced by one with constant real risk-free rate $(r=1.5 \%$, the unconditional mean of the business cycle model), constant market Sharpe ratio $\eta$, and no jumps. I then re-calibrate the firm recovery rate $\alpha$ and idiosyncratic volatility of cash flows $\sigma_{f}$ to match the average recovery rate and 10-year default probability of a Baa-rated firm.

Table IV reports the results. For a Baa-rated firm, with a market Sharpe ratio of 0.3 , the model generates a $50.1 \%$ leverage ratio, ${ }^{8}$ while the 10 -year credit spread is only 57 bps, far short of the spread in the data (148 bps) or the target after adjusting for liquidity and taxes (105 bps). The net tax benefit, defined as the percentage increase in firm value when it takes on optimal leverage, is $11.9 \%$. On the one hand, lowering the market Sharpe ratio to 0.15 appears to help lower the market leverage somewhat, but the credit spread drops to 37.4 bps and the firm is actually taking on a lot more debt, as suggested by its much lower interest coverage (0.5). In fact, the lower market leverage is due to the mispricing of equity - the risk premium is too low (implied by the

equity Sharpe ratio), which raises the value of equity more than debt. On the other hand, raising the market Sharpe ratio sufficiently high (0.5) can help the model eventually match the spread in the data (101.1 bps), but the Sharpe ratio for equity rises to 0.31 , which is counterfactually high as argued by Chen, Collin-Dufresne, and Goldstein (2009), and leverage rises to 52.5\%. These 
discrepancies highlight the dual puzzles of credit spreads and leverage.

\section{Insert Table IV About Here}

Next, I solve the firm's capital structure problem with business cycle risks in all nine initial states. For each initial state, I compute the optimal coupon rate and default/restructuring boundaries. I also compute the 10-year default rate, 10-year restructuring frequency, and credit spread of a 10-year bond with identical default timing and recovery rate as the firm's consol via simulation. Panel A of Table V reports the results. The average debt recovery rate and 10-year default probability match the data closely as a result of the SMM estimation of $\alpha$ and $\sigma_{f}$. On average, the firm restructures its debt 0.5 times in 10 years. The average 10-year credit spread is 104.5 bps, nearly double the value in the case without business cycle risks (for comparable equity Sharpe ratio) and very close to the target spread (105 bps). There is significant variation in the 10-year spreads over time. The volatility of the credit spreads is $35 \mathrm{bps}$, close to the standard deviation of Baa-Aaa spreads in the data (41 bps).

\section{Insert Table V About Here}

The model also generates lower leverage. The average market leverage is $37.4 \%$, as opposed to $50.1 \%$ in the case without business cycle risks. The mean interest coverage is 2.2 , still low compared to the data, but much higher than in the case without business cycle risks (1.3). The net tax benefit is on average $6.2 \%$, in line with the empirical estimates of Graham (2000) and Korteweg (2009). ${ }^{9}$ The average Sharpe ratio of equity is 0.19 , which is consistent with the estimates for Baa-rated firms (0.22) in Chen, Collin-Dufresne, and Goldstein (2009). These results show that business cycle risks go a long way in explaining the observed credit spreads and leverage.

The model generates large variation in debt recovery rates, ranging from $15 \%$ (if default occurs in state 9 ) to $52.5 \%$ (in state 1). The firm's financing policy also varies significantly across states. When the expected growth rate is high and economic uncertainty is low (state 1), the firm is more aggressive in taking on debt, choosing a lower interest coverage (1.1) and higher leverage (50.1\%). As a result, the firm also has a higher conditional default probability (10.5\%) and credit spread (142.7 bps). Because it has already issued more debt, the firm is less likely to increase its debt in 
the next 10 years ( 0.25 times on average) compared to the other states. The net tax benefit also rises to $7.3 \%$.

In contrast, the firm is significantly more conservative when issuing debt in state 9 , where the expected growth rate is low and economic uncertainty is high. Higher economic uncertainty (systematic volatility) not only raises the price of risk for Brownian shocks, but also makes the firm's cash flows more correlated with the market, which causes the firm's default risk to be more systematic. As a result, the optimal leverage drops to $32.1 \%$, and the net tax benefit drops to $4.7 \%$. Notice that the 10-year default probability actually becomes lower (4.2\%) despite the low growth rate and high volatility of cash flows. This suggests that, when possible, the firm will aggressively adjust its financing policy to reduce default risk during bad times.

\section{Insert Figure 4 About Here}

Figure 4 provides more information about the firm's financing policies in different states. Since the firm is less concerned with default risk in good times, the optimal coupon (Panel A) and the optimal market leverage (Panel B) are both procyclical, in the sense that they are higher in those states with low volatility and high growth. However, even though the optimal leverage is procyclical, the actual leverage in the time series is countercyclical in this model. I investigate the dynamic properties of leverage in the next section. Panel $\mathrm{C}$ plots the default boundaries in different states for a firm that issues debt in state 5 (medium volatility and growth). The default boundary is countercyclical - it increases with aggregate volatility and decreases with the expected growth rate, which implies that equity holders will voluntarily default earlier (at higher cash flow levels) in bad times. The higher default boundaries, combined with the lower expected growth rates and higher volatility, generate higher default probabilities in recessions.

Why do firms choose higher default boundaries in bad times? The decision to default can be viewed as exercising a put option. At any point in time, equity holders can retain their claim on future dividends and the option to default by making interest payments. They can also exercise their default option, give up the firm, and walk away. In bad times, the risk premia (discount rates) are higher (partly caused by higher systematic volatility), while the expected growth rates of cash flows are lower. Both effects will lower the present value of future cash flows. This reduces the 
continuation value for equity holders, making them more reluctant to keep the firm alive. I refer to the first effect as the "discount rate effect," the second as the "cash flow effect." Next, higher volatility in bad times also makes the option to default more valuable, in which case the firm may defer the timing of default. This is the "volatility effect." In the model, the discount rate effect and cash flow effect dominate the volatility effect, which causes firms to default earlier in bad times.

Similar intuition suggests that firms are more reluctant to increase their debt in bad times, which is confirmed by the countercyclical restructuring boundaries in Panel D. A comparison between Panels $\mathrm{C}$ and $\mathrm{D}$ shows that the restructuring boundaries are more sensitive to changes in volatility than the default boundaries. Intuitively, the discount rate effect suggests that higher systematic volatility leads to higher risk premia, which lowers the present value of future tax benefits and reduces the firm's incentive to lever up. The volatility effect suggests that higher volatility makes the option to lever up more valuable, which causes firms to wait longer before exercising this option. Unlike in the case of default where these two effects offset each other, here they work in the same direction to push up the restructuring boundaries.

Panel E plots the asset value at the time of default as a fraction of initial asset value in state 5 , which gives the asset value default boundary. Due to lower expected growth rate and higher risk premium, the asset value default boundary is lower in bad times (procyclical), even though the default boundary based on cash flow is higher in bad times. This result highlights the difference between measuring the default boundary by asset value and by cash flow when the ratio of the two is not constant. It should be an important consideration when calibrating structural models with exogenous default boundaries.

Finally, Panel F plots the default loss in different states as a fraction of initial firm value. To compute the default loss, at the default boundary of each state, I first compute the value of the firm assuming it is optimally levered. The difference between this value and the value recovered by debt holders is the default loss. ${ }^{10}$ In six out of nine states, the default losses are below $1.7 \%$ of initial firm value, and the unconditional average is $2.3 \%$. However, the losses become significantly higher in the three states with low growth rates, reaching $10 \%$ in the state with high economic uncertainty. To see whether the size of these default losses is economically plausible, consider that Andrade and Kaplan (1998) estimate the costs of financial distress to be between $10 \%$ and $20 \%$ of 
pre-distress firm value. This would translate to $2 \%$ to $4 \%$ of initial firm value assuming that the firm's value has fallen by $80 \%$ from normal times to the onset of financial distress.

The countercyclical variation in default losses is crucial for generating low leverage. Even though the average default loss appears to be quite small, big losses in bad states with high risk premia will deter firms from choosing high leverage. To demonstrate this effect, I conduct a comparative static exercise by fixing the firm recovery rate $\alpha$ at its unconditional mean. The default loss in each state will then be a constant proportion of the asset value at default. The results are in Panel B of Table V. On average, the optimal leverage jumps to 53.6\%, even higher than in the case without business cycle risks (with comparable equity Sharpe ratio), while the average interest coverage drops to 1.3. The net tax benefit also rises significantly. Moreover, the 10-year default probability becomes much higher $(17 \%)$. If we recalibrate the model to bring down the default probability (by reducing idiosyncratic volatility $\sigma_{f}$ ), the firm will issue even more debt. Part of the reason for the higher leverage in this case is that, when $\alpha$ is constant, procyclical variation in asset value at default leads to lower default losses in bad times, which then generates a negative risk premium on the defaultable claim for equity holders (the levered firm). Compared with the benchmark firm, the firm with constant recovery rate also restructures its debt more frequently to take advantage of the tax benefits.

These results highlight the central role that countercyclical default losses play in explaining the leverage puzzle. Firms are reluctant to take on leverage not because the default losses are high on average, but because the losses are particularly high in those states in which defaults are more likely and losses are harder to bear.

Besides the countercyclical default losses, I also investigate the effects of jump risks and systematic Brownian risks on the capital structure and credit spreads.

First, part of the systematic risks that the firm faces in this economy is jump risk: jumps in the value of the firm's assets are priced because they coincide with the jumps in the stochastic discount factor, both driven by the large and persistent business cycle shocks in the economy. Panel A of Table VI shows how much of benchmark firm's high credit spread and low leverage are accounted for by the jump-risk premium. I set the systematic volatility $\sigma_{X, m}\left(s_{t}\right)$ to zero $\left(b_{f}=\sigma_{f, m}=0\right)$, thus removing the firm's exposure to systematic Brownian risks. At the same time, I raise the 
idiosyncratic volatility $\sigma_{f}$ to 0.29 so that the average 10 -year default rate is still $4.9 \%$. With only jump risks, the equity Sharpe ratio drops to 0.09 on average. The average 10-year credit spread is 65 bps, which is 40 bps less than for the benchmark firm, but 28 bps higher than in the case without business cycle risks (for the same equity Sharpe ratio) or 36 bps higher than in a model with no systematic risk at all. Thus, in this model, the jump-risk premium accounts for about half of the credit risk premium in Baa-rated bonds.

\section{Insert Table VI About Here}

Because of the low equity Sharpe ratio, we cannot directly compare the market leverage of this firm with the benchmark firm. Instead, interest coverage is a better measure of leverage in this case. The interest coverage for the firm with only jump risks is on average one, compared to 2.2 for the benchmark firm, but it is double the value in the case without business cycle risks. These results imply that both the jump risks and the systematic Brownian risks are essential for the model to generate reasonable credit spreads and leverage ratios.

Second, if a firm's cash flows are more correlated with the market, changes in the aggregate expected growth rate and volatility across different states will have a larger impact on its cash flows. The firm's default timing will thus become more systematic, that is, defaults are more likely to occur in those states with low growth and high economic uncertainty, which will raise the credit spread and reduce the firm's incentive to take on debt. There are two ways to make the firm's cash flows more correlated with the market: (1) increase the instantaneous correlation between the growth rates of firm cash flows and aggregate output; and (2) reduce the total volatility of Brownian shocks, thus making the expected growth rate a more important source of future variation in cash flows.

We can achieve both effects simultaneously by lowering the idiosyncratic volatility of cash flows $\sigma_{f}$ while holding the other parameters the same as in the benchmark case. An interesting way to re-calibrate $\sigma_{f}$ is to match the 10-year default probability of the firm with that of an Aaa-rated firm in the data $(0.6 \%)$, which gives $\sigma_{f}=0.153$. Indeed, Table VI Panel B shows that the new firm issues less debt relative to the benchmark firm, as measured by interest coverage, even though its cash flows are less volatile. The higher systematic risks raise the equity Sharpe ratio to 0.24 on 
average. The average 10-year credit spread is $38 \mathrm{bps}$, which might appear surprisingly high given the low probability of default. As Figure 5 shows, compared to the benchmark firm, default of the firm that is more correlated with the market is more likely to occur in those bad states with high risk premia and high default losses. Such systematic defaults explain the firm's high credit spreads despite its low average default probability.

\section{Insert Figure 5 About Here}

However, the market leverage of this firm (37\% on average) is still considerably higher than that of the Aaa firms in the data, which tend to have large cash holdings and little debt. In a trade-off model, there is tension between generating low default probability and low leverage: lowering the volatility of cash flows will tend to lower the former, but raise the latter. Moreover, Aaa firms in the data are likely to be less correlated with the market than implied by the calibration above, which would further raise the optimal leverage in the model. Thus, a simple trade-off model like the one in this paper is unlikely to explain the low leverage ratios for Aaa firms in the data.

Based on these results, we can infer what would happen if we increase the idiosyncratic volatility of the firm's cash flows instead, perhaps to match the default probability of a junk-rated firm. The correlation of the firm's cash flows with the market would drop, making the default risk of the firm less systematic. As a result, the equity Sharpe ratio and the credit risk premium would fall, and the firm will take on higher leverage.

\section{Dynamics of Leverage and Defaults}

So far, we have mostly focused on the firm's optimal financing decisions and corporate bond pricing at $t=0$. To illustrate the dynamic properties of market leverage, countercyclical default rates, and clustering of defaults, I simulate a cohort of 1,000 firms over 200 years. These firms have the same cash flow parameters as the benchmark firm and receive the same aggregate shocks, but they experience different idiosyncratic shocks. To maintain a balanced panel, I assume that whenever an existing firm defaults, a new firm is born and inherits the cash flows of the defaulted firm. At the end of each month, I compute the aggregate market leverage and default rates.

Panel A of Figure 6 plots the time series of aggregate market leverage. The shaded areas 
denote the times when the economy is in state 7,8 , or 9 , where expected consumption growth is negative, which can be interpreted as recessions. Even though the optimal (target) leverage ratio is procyclical in this model (see Figure 4, Panel B), the actual leverage is countercyclical. Firms cannot costlessly adjust their leverage downward upon entering into a bad state. Instead, when recessions arrive, they are stuck with the debt issued in good times, and the leverage ratio is likely to rise because the value of equity falls more than debt during these times.

\section{Insert Figure 6 About Here}

Panel B shows that default rates are also countercyclical. In fact, most defaults occur at times when the economy is in a recession. Moreover, there are several spikes in default rates that occur right at the time when the economy is entering into a recession. These spikes are examples of default waves: a number of firms default at the same time. These clustered defaults are due to a sudden deterioration of macroeconomic conditions that causes firms' default boundaries to jump up, so that those firms with cash flows below the new default boundaries will default simultaneously.

Following the clustered defaults, the conditional default probabilities and credit spreads of the rest of the firms rise. Such phenomena resemble credit contagion, whereby the credit spreads of other firms jump up following a wave of defaults. However, in this model, the same large macroeconomic shocks that cause a group of firms to default together are what raise the default risks of the other firms.

The model also generates waves of debt issuances. The monthly rates of debt issuance are procyclical, and they often spike up when the economy switches from a bad state to a good state, implying that many firms issue debt at the same time. Since credit spreads (borrowing costs) drop when macroeconomic conditions improve, these firms behave like market timers, issuing more debt when interest rates become lower.

\section{Downward Restructuring and Cash Holdings}

An important limitation of this model is the assumption that the firm cannot hold cash or reduce its debt when it is in financial distress. I conclude this section by discussing what effects these features might have on the main results of this model. Intuitively, allowing a firm to save cash 
"for a rainy day" or to reorganize its debt while in distress (through asset sales or debt-for-equity swaps) would make it easier for the firm to avoid default. Does this mean that the model will generate higher leverage after adding these features?

Not necessarily. After extending the model with these new features, we still need to recalibrate the parameters to match the default probabilities and debt recovery rates in the data. Thus, after re-calibration, downward restructuring or cash holdings will not lower the firm's average default probability. Instead, what matters is how these features change the distribution of default across different states, which depends on the trade-off between the costs and benefits of restructuring or holding cash across states.

In the case of downward restructuring, the costs of restructuring are likely to be significantly higher in bad times. If the differences in restructuring costs across states are sufficiently large, the option to restructure can actually increase the differences in default probabilities across states (consider the extreme case where restructuring is costless in good times but not allowed in bad times). Holding the average default probability fixed, this means default probabilities will rise in bad times and fall in good times. The default risk of the firm will thus become more systematic, and the firm will issue less debt.

Similarly, while the firm does have an incentive to hoard cash to lower its probability of default (especially in bad times), whether cash holdings help the firm more in reducing its default probability in good times or bad times depends on the trade-off between the marginal benefit (lowering default losses) and cost of holding cash in different states. In bad times, the marginal cost of cash will be higher, as high costs of external financing and low profitability make it more difficult for a firm to maintain a high cash balance. Thus, it is possible that the firm ends up holding more cash in good times, which helps lower the probability of default in good times relative to bad times. In that case, leverage will again become lower.

These arguments by no means imply that we can ignore the effects of downward restructuring and cash holdings in determining firms' capital structure. Instead, they serve to highlight the key mechanism of this model, that is, the countercyclical default probabilities and default losses that arise endogenously from firm decisions, which should also be an important consideration when we examine the true impact of downward restructuring and cash holdings on other dimensions of 
financial policy in the context of a dynamic trade-off model.

\section{Concluding Remarks}

Macroeconomic conditions influence firm decisions, which in turn affect the riskiness of the firms. Thus, a better understanding of corporate decisions and frictions in a realistic macroeconomic environment will help us better assess the risks associated with various corporate securities.

I build a dynamic capital structure model to examine how firms make financing decisions over the business cycle. The firms' endogenous decisions with respect to leverage, restructuring, and default, in response to time variation in expected growth rates, economic uncertainty, and risk premia, help explain the countercyclical comovements among risk prices, default probabilities, and default losses. Firms that are more correlated with the market have defaults and default losses that are more concentrated in bad times, when marginal utility is high, in which case investors will demand high risk premia on their defaultable claims. The credit risk premia can quantitatively account for the high credit spreads and low leverage ratios of Baa-rated firms in the data. The model also generates interesting dynamics of financing and default. For example, it provides a rational mechanism for "credit contagion" and market timing of debt issuance. The paper further provides a novel procedure to estimate state-dependent default losses.

To highlight the effects of macroeconomic conditions and risk premia on firms' financing decisions, I use the setting of a simple trade-off model, which abstracts from many interesting aspects of corporate decisions, such as cash holdings, investments, agency costs, strategic debt servicing, downward restructuring, etc. It would be useful to study how macroeconomic conditions interact with these different elements in corporate finance. I leave these questions to future research. 


\section{Appendix}

\section{A. Proof of Proposition 1}

To obtain the stochastic discount factor, I first solve for the value function of the representative household. In equilibrium, the representative household consumes aggregate output, which is given in (4). Thus, I directly define the value function of the representative agent as

$$
J\left(Y_{t}, s_{t}\right)=E_{t}\left[\int_{0}^{\infty} f\left(Y_{t+s}, J_{t+s}\right) d s\right]
$$

The Hamilton-Jacoby-Bellman equation in state $i$ (for $i=1, \cdots, n)$ is

$$
0=f(Y, J(Y, i))+J_{Y}(Y, i) Y \theta_{m}(i)+\frac{1}{2} J_{Y Y}(Y, i) Y^{2} \sigma_{m}^{2}(i)+\sum_{j \neq i} \lambda_{i j}(J(Y, j)-J(Y, i))
$$

Conjecture that the solution for $J$ is

$$
J(Y, s)=\frac{(h(s) Y)^{1-\gamma}}{1-\gamma}
$$

Substituting $J$ into the differential equations above, we get the following system of nonlinear equations for $h$ :

$$
\begin{aligned}
0 & =\rho \frac{1-\gamma}{1-\delta} h(i)^{\delta-\gamma}+\left[(1-\gamma) \theta_{m}(i)-\frac{1}{2} \gamma(1-\gamma) \sigma_{m}^{2}(i)-\rho \frac{1-\gamma}{1-\delta}\right] h(i)^{1-\gamma} \\
& +\sum_{j \neq i} \lambda_{i j}\left(h(j)^{1-\gamma}-h(i)^{1-\gamma}\right), \quad i=1, \cdots, n
\end{aligned}
$$

where $\delta=1 / \psi$. These equations can be solved easily using a nonlinear equation solver, even when the number of states is fairly large.

Duffie and Epstein (1992b) and Duffie and Skiadas (1994) show that the stochastic discount factor is equal to

$$
m_{t}=e^{\int_{0}^{t} f_{v}\left(c_{u}, J_{u}\right) d u} f_{c}\left(c_{t}, J_{t}\right)
$$

Plugging $J$ and $Y$ into (A5) and applying Ito's formula with jumps (see, for example, Duffie (2001)), we get 
equation (5), where

$$
\begin{aligned}
r(i)= & -\frac{\rho(1-\gamma)}{1-\delta}\left[\left(\frac{\delta-\gamma}{1-\gamma}\right) h(i)^{\delta-1}-1\right]+\gamma \theta_{m}(i) \\
& -\frac{1}{2} \gamma(1+\gamma) \sigma_{m}^{2}(i)-\sum_{j \neq i} \lambda_{i j}\left(e^{\kappa(i, j)}-1\right), \\
\eta(i)= & \gamma \sigma_{m}(i), \\
\kappa(i, j)= & (\delta-\gamma) \log \left(\frac{h(j)}{h(i)}\right) .
\end{aligned}
$$

Q.E.D.

\section{B. Value of Debt and Equity}

We define the risk-neutral measure $\mathcal{Q}$ associated with the nominal stochastic discount factor $n_{t}=m_{t} / P_{t}$ (see the Internet Appendix for details). The risk-neutral dynamics of the $\log$ nominal cash flow $x_{t}=\ln \left(X_{t}\right)$ of the firm are

$$
d x_{t}=\left(\tilde{\theta}_{X}\left(s_{t}\right)-\frac{1}{2} \sigma_{X}^{2}\left(s_{t}\right)\right) d t+\sigma_{X}\left(s_{t}\right) d \tilde{W}_{t}^{f}
$$

where

$$
\begin{aligned}
& \tilde{\theta}_{X}\left(s_{t}\right)=\theta_{X}\left(s_{t}\right)-\sigma_{X, m}\left(s_{t^{-}}\right) \eta^{m}\left(s_{t^{-}}\right)-\sigma_{P, 2} \eta^{P}, \\
& \sigma_{X}\left(s_{t}\right)=\sqrt{\sigma_{X, m}^{2}\left(s_{t}\right)+\sigma_{P, 2}^{2}+\sigma_{f}^{2}},
\end{aligned}
$$

and $\tilde{W}_{t}^{f}$ is a standard Brownian motion under $\mathcal{Q}$.

Next, consider a corporate contingent claim $J\left(x_{t}, s_{t}\right)$, which pays dividends at the rate $F\left(x_{t}, s_{t}\right)$ when the firm is solvent, a default payment $H\left(x_{\tau_{D}}, s_{\tau_{D}}\right)$ when default occurs at time $\tau_{D}$, and a restructuring payment $K\left(x_{\tau_{U}}, s_{\tau_{U}}\right)$ when restructuring occurs at time $\tau_{U}$. Let $\mathbf{F}(x), \mathbf{H}(x), \mathbf{K}(x)$, and $\mathbf{J}(x)$ be $n \times 1$ vectors with their $i$ th elements equal to $F(x, i), H(x, i), K(x, i)$, and $J(x, i)$, respectively.

I define an $n \times n$ diagonal matrix $\mathcal{A}$. Its $i$ th diagonal element $\mathcal{A}^{i}$ is the infinitesimal generator for any $\mathcal{C}^{2}$ function $\phi(x)$ in state $i$, where $x$ is the log nominal cash flow specified in (A11):

$$
\mathcal{A}^{i} \phi(x)=\left(\tilde{\theta}_{X}(i)-\frac{1}{2} \sigma_{X}^{2}(i)\right) \frac{\partial}{\partial x} \phi(x)+\frac{1}{2} \sigma_{X}^{2}(i) \frac{\partial^{2}}{\partial x^{2}} \phi(x)
$$

Suppose we have the following default/restructuring boundaries: $\left(X_{D}^{1}, \cdots, X_{D}^{n}, X_{U}^{u(1)}, \cdots, X_{U}^{u(n)}\right)$. When cash flow $X$ is in the region $\mathcal{D}_{k}=\left[X_{D}^{k}, X_{D}^{k+1}\right)$ for $k=1, \cdots, n-1$, the firm will already be in default in the 
states $s>k$. Thus, the security will only be "alive" in the first $k$ states. Let the index set $\mathcal{I}_{k}=\{1, \ldots, k\}$ denote the states in which the firm would not have defaulted yet (given $X \in \mathcal{D}_{k}$ ), and its complement $\mathcal{I}_{k}^{c}=\{k+1, \ldots, n\}$ denote the states in which the firm would have defaulted already. Similarly, when $X \in \mathcal{D}_{n+k}=\left(X_{U}^{u(k)}, X_{U}^{u(k+1)}\right]$ for $k=1, \cdots, n-1$, I use index set $\mathcal{I}_{n+k}=\{u(k+1), \cdots, u(n)\}$ to denote states in which the firm has not yet restructured, with its compliment $\mathcal{I}_{n+k}^{c}=\{u(1), \cdots, u(k)\}$ denoting the states in which restructuring has occurred.

When $X \in \mathcal{D}_{k}(k \leq n-1)$, the claims that are not in default yet are $\mathbf{J}_{\left[\mathcal{I}_{k}\right]}$. The Feynman-Kac formula implies that $\mathbf{J}_{\left[\mathcal{I}_{k}\right]}$ satisfies the following system of ordinary differential equations:

$$
\mathcal{A}_{\left[\mathcal{I}_{k}, \mathcal{I}_{k}\right]} \mathbf{J}_{\left[\mathcal{I}_{k}\right]}+\mathbf{F}_{\left[\mathcal{I}_{k}\right]}+\tilde{\Lambda}_{\left[\mathcal{I}_{k}, \mathcal{I}_{k}\right]} \mathbf{J}_{\left[\mathcal{I}_{k}\right]}+\tilde{\Lambda}_{\left[\mathcal{I}_{k}, \mathcal{I}_{k}^{c}\right]} \mathbf{H}_{\left[\mathcal{I}_{k}^{c}\right]}=\mathbf{r}_{\left[\mathcal{I}_{k}, \mathcal{I}_{k}\right]}^{n} \mathbf{J}_{\left[\mathcal{I}_{k}\right]}
$$

In regions $\mathcal{D}_{n}$, a sudden change of state will not cause immediate default or restructuring. Thus,

$$
\mathcal{A} \mathbf{J}+\mathbf{F}+\tilde{\Lambda} \mathbf{J}=\mathbf{r}^{n} \mathbf{J}
$$

When $X \in \mathcal{D}_{n+k}(k \leq n-1)$, the firm has not restructured yet in those states in $\mathcal{I}_{n+k}$, where

$$
\mathcal{A}_{\left[\mathcal{I}_{n+k}, \mathcal{I}_{n+k}\right]} \mathbf{J}_{\left[\mathcal{I}_{n+k}\right]}+\mathbf{F}_{\left[\mathcal{I}_{n+k}\right]}+\tilde{\Lambda}_{\left[\mathcal{I}_{n+k}, \mathcal{I}_{n+k}\right]} \mathbf{J}_{\left[\mathcal{I}_{n+k}\right]}+\tilde{\Lambda}_{\left[\mathcal{I}_{n+k}, \mathcal{I}_{n+k}^{c}\right]} \mathbf{K}_{\left[\mathcal{I}_{n+k}^{c}\right]}=\mathbf{r}_{\left[\mathcal{I}_{n+k}, \mathcal{I}_{n+k}\right]}^{n} \mathbf{J}_{\left[\mathcal{I}_{n+k}\right]}
$$

The homogeneous equation from (A13) and (A14) can be formulated as a quadratic eigenvalue problem. Jobert and Rogers (2006) show that its solution takes the form

$$
\mathbf{J}(x)_{\left[\mathcal{I}_{k}\right]}=\sum_{j=1}^{2 k} w_{k, j} \mathbf{g}_{k, j} \exp \left(\beta_{k, j} x\right)
$$

where $\mathbf{g}_{k, j}$ and $\beta_{k, j}$ are solutions to the following standard eigenvalue problem:

$$
\left[\begin{array}{cc}
0 & \mathbf{I} \\
-\left(2 \boldsymbol{\Sigma}_{X}^{-1}\left(\tilde{\boldsymbol{\Lambda}}-\mathbf{r}^{n}\right)\right)_{\left[\mathcal{I}_{k}, \mathcal{I}_{k}\right]} & -\left(2 \boldsymbol{\Sigma}_{X}^{-1} \tilde{\theta}_{X}-\mathbf{I}\right)_{\left[\mathcal{I}_{k}, \mathcal{I}_{k}\right]}
\end{array}\right]\left[\begin{array}{l}
\mathbf{g}_{k} \\
\mathbf{h}_{k}
\end{array}\right]=\beta_{k}\left[\begin{array}{l}
\mathbf{g}_{k} \\
\mathbf{h}_{k}
\end{array}\right]
$$

where $\mathbf{I}$ is an $n \times n$ identity matrix, $\mathbf{r}^{n}=\operatorname{diag}\left(\left[r^{n}(1), \cdots, r^{n}(n)\right]^{\prime}\right), \tilde{\theta}_{X}=\operatorname{diag}\left(\left[\tilde{\theta}_{X}(1), \cdots, \tilde{\theta}_{X}(n)\right]^{\prime}\right)$, and $\boldsymbol{\Sigma}_{X}=\operatorname{diag}\left(\left[\sigma_{X}^{2}(1), \cdots, \sigma_{X}^{2}(n)\right]^{\prime}\right)$. The coefficients $w_{k, j}$ will be different for different securities. 
Similarly, the solution to the homogeneous equation from (A15) is

$$
\mathbf{J}(x)_{\left[\mathcal{I}_{n+k}\right]}=\sum_{j=1}^{2(n-k+1)} w_{n+k, j} \mathbf{g}_{n+k, j} \exp \left(\beta_{n+k, j} x\right)
$$

where $\mathbf{g}_{n+k, j}$ and $\beta_{n+k, j}$ are solutions to the following standard eigenvalue problem:

$$
\left[\begin{array}{c}
0 \\
-\left(2 \boldsymbol{\Sigma}_{X}^{-1}\left(\tilde{\mathbf{\Lambda}}-\mathbf{r}^{n}\right)\right)_{\left[\mathcal{I}_{n+k}, \mathcal{I}_{n+k}\right]}^{\mathbf{I}}
\end{array}\right]\left[\begin{array}{l}
\mathbf{g}_{n+k} \\
\mathbf{h}_{n+k}
\end{array}\right]=\beta_{n+k}\left[\begin{array}{l}
\mathbf{g}_{n+k} \\
\mathbf{h}_{n+k}
\end{array}\right] .
$$

The remaining tasks are to find the particular solutions for the inhomogeneous equations, and solve for the coefficients $w_{k, j}$ through the boundary conditions, which depend on the dividend rate $F$, default payment $H$, and restructuring payment $K$ of the specific security.

Debt. Let $D\left(x, s ; s_{0}\right)$ be the value of debt after debt is issued, where $s_{0}$ shows the dependence of the debt value on the state at time 0 through initial coupon $C\left(s_{0}\right)$. The "dividend" for debt is the after-tax coupon. With strict priority, the default payment is equal to the recovery value of the firm. At the time of restructuring, debt from previous issues is called at par, that is, the initial value of debt at issuance. Thus,

$$
\begin{aligned}
& F\left(X, s ; s_{0}\right)=\left(1-\tau_{i}\right) C\left(s_{0}\right), \\
& H\left(X, s ; s_{0}\right)=\alpha(s) V(X, s), \\
& K\left(X, s ; s_{0}\right)=D\left(X_{0}, s_{0} ; s_{0}\right),
\end{aligned}
$$

where $V$ is the value of the unlevered firm as given in (18).

Define vector $\mathbf{D}\left(X ; s_{0}\right)=\left[D\left(X, 1 ; s_{0}\right), \cdots, D\left(X, n ; s_{0}\right)\right]^{\prime}$, which satisfies (A13), (A14), or (A15) depending on the value of $X$. The solution to the homogeneous equations follows directly from (A16) or (A18). I specify the particular solutions below, and leave the details of the derivation to the Internet Appendix.

When $X \in \mathcal{D}_{k}(k=1, \cdots, n-1)$, for any state $i \in \mathcal{I}_{k}$, a particular solution is

$$
\mathbf{D}\left(x ; s_{0}\right)_{\left[\mathcal{I}_{k}\right]}=\xi_{k}^{D}\left(\mathcal{I}_{k} ; s_{0}\right) e^{x}+\zeta_{k}^{D}\left(\mathcal{I}_{k} ; s_{0}\right),
$$

where

$$
\begin{aligned}
& \xi_{k}^{D}\left(\mathcal{I}_{k} ; s_{0}\right)=\left(\mathbf{r}^{n}-\tilde{\mathbf{\Lambda}}-\tilde{\theta}_{X}\right)_{\left[\mathcal{I}_{k}, \mathcal{I}_{k}\right]}^{-1}\left(\tilde{\boldsymbol{\Lambda}}_{\left[\mathcal{I}_{k}, \mathcal{I}_{k}^{c}\right]}(\alpha \odot \mathbf{v})_{\left[\mathcal{I}_{k}^{c}\right]}\right), \\
& \zeta_{k}^{D}\left(\mathcal{I}_{k} ; s_{0}\right)=\left(1-\tau_{i}\right) C\left(s_{0}\right)\left(\mathbf{r}^{n}-\tilde{\mathbf{\Lambda}}\right)_{\left[\mathcal{I}_{k}, \mathcal{I}_{k}\right]}^{-1} \mathbf{1}_{k} .
\end{aligned}
$$


The symbol $\odot$ denotes element-by-element multiplication; $\alpha$ is an $n \times 1$ vector of recovery rates and $\mathbf{v}$ is given in (19).

In the region $\mathcal{D}_{n}$, a particular solution is

$$
\mathbf{D}\left(x ; s_{0}\right)=\zeta_{n}^{D}=\left(1-\tau_{i}\right) C\left(s_{0}\right) \mathbf{b} .
$$

When $X \in \mathcal{D}_{n+k}(k=1, \cdots, n-1)$, a particular solution is

$$
\mathbf{D}\left(x ; s_{0}\right)_{\left[\mathcal{I}_{n+k}\right]}=\zeta_{n+k}^{D}\left(\mathcal{I}_{n+k} ; s_{0}\right)
$$

where

$$
\zeta_{n+k}^{D}\left(\mathcal{I}_{n+k} ; s_{0}\right)=\left(\mathbf{r}^{n}-\tilde{\boldsymbol{\Lambda}}\right)_{\left[\mathcal{I}_{n+k}, \mathcal{I}_{n+k}\right]}^{-1}\left[\left(1-\tau_{i}\right) C\left(s_{0}\right) \mathbf{1}_{n-k}+\tilde{\boldsymbol{\Lambda}}_{\left[\mathcal{I}_{n+k}, \mathcal{I}_{n+k}^{c}\right]} \mathbf{1}_{k} D\left(X_{0}, s_{0} ; s_{0}\right)\right]
$$

Notice that $\zeta_{n+k}^{D}$ cannot be solved explicitly yet because $D\left(X_{0}, s_{0} ; s_{0}\right)$ depends on the unknown coefficients $w_{n, j}^{D}$. Since $D\left(X_{0}, s_{0} ; s_{0}\right)$ is linear in $w_{n, j}^{D}$, so will be $\zeta_{n+k}^{D}$, which is key when we solve for $w_{n, j}^{D}$ in a linear system.

Next, I specify the boundary conditions that determine the coefficients $w_{k, j}^{D}$. First, there are $n$ conditions specifying the value of debt at the $n$ default boundaries:

$$
D\left(X_{D}^{i}, i ; s_{0}\right)=\alpha(i) V\left(X_{D}^{i}, i\right), \quad i=1, \cdots, n .
$$

Another $n$ conditions specify the value of debt at the restructuring boundaries:

$$
D\left(X_{U}^{u(i)}, u(i) ; s_{0}\right)=D\left(X_{0}, s_{0} ; s_{0}\right), \quad i=1, \cdots, n .
$$

Because the payoff function $F$ and terminal payoffs $H$ and $K$ are bounded and piecewise-continuous in $X$, while the discount rate $r$ is constant in each state, $D(X, s)$ must be piecewise $\mathcal{C}^{2}$ with respect to $X$ (see Karatzas and Shreve (1991)), which implies that $D$ is continuous and smooth at all the boundaries for which neither default or restructure has occurred. Thus, for $k=1, \cdots, n-1$,

$$
\begin{aligned}
\lim _{X \uparrow X_{D}^{k+1}} D\left(X, i ; s_{0}\right) & =\lim _{X \downarrow X_{D}^{k+1}} D\left(X, i ; s_{0}\right), \\
\lim _{X \uparrow X_{D}^{k+1}} D_{X}\left(X, i ; s_{0}\right) & =\lim _{X \downarrow X_{D}^{k+1}} D_{X}\left(X, i ; s_{0}\right), \quad i \in \mathcal{I}_{k} .
\end{aligned}
$$


and

$$
\begin{aligned}
\lim _{X \uparrow X_{U}^{u(k)}} D\left(X, u(i) ; s_{0}\right) & =\lim _{X \downarrow X_{U}^{u(k)}} D\left(X, u(i) ; s_{0}\right), \\
\lim _{X \uparrow X_{U}^{u(k)}} D_{X}\left(X, u(i) ; s_{0}\right) & =\lim _{X \downarrow X_{U}^{u(k)}} D_{X}\left(X, u(i) ; s_{0}\right), \quad i \in \mathcal{I}_{n+k} .
\end{aligned}
$$

There are $2 n^{2}$ unknown coefficients in $\left\{w^{D}\left(s_{0}\right)\right\}$ and $2 n^{2}$ boundary conditions for each $s_{0}$. All the boundary conditions in (A28) through (A31) are linear in the unknowns, which gives us a system of $2 n^{2}$ linear equations that can be solved in closed form.

Equity. Let $E\left(x, s ; s_{0}\right)$ be the value of equity after debt is issued, where $s_{0}$ again represents the dependence of equity value on the coupon chosen at time 0. For equity, with full loss offset, the dividend is equal to cash flow net of interest expenses and corporate/personal taxes. At default, equity holders recover nothing. At the time of debt restructuring, the value of equity is equal to the net proceeds from new debt issuance, minus the issuance costs, plus the equity claim after restructuring. That is,

$$
\begin{aligned}
& F\left(X, s ; s_{0}\right)=\left(1-\tau_{d}\right)\left(1-\tau_{c}\right)\left(X-C\left(s_{0}\right)\right), \\
& H\left(X, s ; s_{0}\right)=0, \\
& K\left(X, s ; s_{0}\right)=(1-q) D(X, s ; s)-D\left(X_{0}, s_{0} ; s_{0}\right)+E(X, s ; s),
\end{aligned}
$$

where $E(X, s ; s)$ is the value of equity the instant after restructuring when restructuring occurs in state $s$. Applying the scaling property to the restructuring payment, we can rewrite $K\left(X, s ; s_{0}\right)$ as a linear function of $X$ :

$$
K\left(X, s ; s_{0}\right)=\left((1-q) D\left(X_{0}, s ; s\right)+E\left(X_{0}, s ; s\right)\right) \frac{X}{X_{0}}-D\left(X_{0}, s_{0} ; s_{0}\right) .
$$

The solutions for $E(X, s)$ take a similar form as debt $D(X, s)$. Again, I only specify the particular solutions below, which takes the form $\xi_{k}^{E}\left(\mathcal{I}_{k} ; s_{0}\right) X+\zeta_{k}^{E}\left(\mathcal{I}_{k} ; s_{0}\right)$, and leave the details to the Internet Appendix.

When $X \in \mathcal{D}_{k}(k=1, \cdots, n)$, for $i \in \mathcal{I}_{k}$,

$$
\begin{aligned}
& \xi_{k}^{E}\left(\mathcal{I}_{k} ; s_{0}\right)=\left(1-\tau_{c}\right)\left(1-\tau_{d}\right)\left(\mathbf{r}^{n}-\tilde{\theta}_{X}-\tilde{\mathbf{\Lambda}}\right)_{\left[\mathcal{I}_{k}, \mathcal{I}_{k}\right]}^{-1} \mathbf{1}_{k} \\
& \zeta_{k}^{E}\left(\mathcal{I}_{k} ; s_{0}\right)=-\left(1-\tau_{c}\right)\left(1-\tau_{d}\right) C\left(s_{0}\right)\left(\mathbf{r}^{n}-\tilde{\boldsymbol{\Lambda}}\right)_{\left[\mathcal{I}_{k}, \mathcal{I}_{k}\right]}^{-1} \mathbf{1}_{k}
\end{aligned}
$$


When $X \in \mathcal{D}_{n+k}(k=1, \cdots, n-1)$, for $i \in \mathcal{I}_{n+k}$,

$$
\begin{aligned}
\xi_{n+k}^{E}\left(\mathcal{I}_{n+k} ; s_{0}\right) & =\left(\mathbf{r}^{n}-\tilde{\theta}_{X}-\tilde{\mathbf{\Lambda}}\right)_{\left[\mathcal{I}_{n+k}, \mathcal{I}_{n+k}\right]}^{-1} \\
& \times\left[\left(1-\tau_{d}\right)\left(1-\tau_{c}\right) \mathbf{1}_{n-k}+\tilde{\boldsymbol{\Lambda}}_{\left[\mathcal{I}_{n+k}, \mathcal{I}_{n+k}^{c}\right.} \frac{\left.\left((1-q) \mathbf{D}\left(X_{0}\right)+\mathbf{E}\left(X_{0}\right)\right)_{\left[\mathcal{I}_{n+k}^{c}\right]}\right]}{X_{0}}\right] \\
\zeta_{n+k}^{E}\left(\mathcal{I}_{n+k} ; s_{0}\right) & \left.=\left(\mathbf{r}^{n}-\tilde{\boldsymbol{\Lambda}}\right)_{\left[\mathcal{I}_{k}, \mathcal{I}_{k}\right]}^{-1}\left[-\tilde{\boldsymbol{\Lambda}}_{\left[\mathcal{I}_{n+k}, \mathcal{I}_{n+k}^{c}\right.}\right]_{k} D\left(X_{0}, s_{0} ; s_{0}\right)-\left(1-\tau_{d}\right)\left(1-\tau_{c}\right) C\left(s_{0}\right) \mathbf{1}_{n-k}\right],
\end{aligned}
$$

where $\mathbf{D}\left(X_{0}\right)$ is an $n \times 1$ vector with the $i$ th element $D\left(X_{0}, i ; i\right)$, and $\mathbf{E}\left(X_{0}\right)$ is defined similarly. Notice that equation (A37) introduces dependence of $\mathbf{E}\left(X ; s_{0}\right)$ on all the $\left\{w^{E}(s)\right\}$ through $\mathbf{E}\left(X_{0}\right)$, not just $\left\{w^{E}\left(s_{0}\right)\right\}$.

The boundary conditions for $E$ are similar to those for debt. First, there are the conditions specifying the value of equity at the default and restructuring boundaries. For $i=1, \cdots, n$,

$$
E\left(X_{D}^{i}, i ; s_{0}\right)=0
$$

and

$$
E\left(X_{U}^{u(i)}, u(i) ; s_{0}\right)=\frac{X_{U}^{u(i)}}{X_{0}}\left((1-q) D\left(X_{0}, u(i) ; u(i)\right)+E\left(X_{0}, u(i) ; u(i)\right)\right)-D\left(X_{0}, s_{0} ; s_{0}\right)
$$

Moreover, we need to ensure that $E$ is continuous and smooth at each default/restructuring boundary, which leads to an identical set of value-matching and smooth-pasting conditions as in the case of debt (see (A30) and (A31)).

The following proposition summarizes the above results.

PROPOSITION 2: Suppose that, at time 0 , the firm will issue a consol with coupon rate $C\left(s_{0}\right)$ in state $s_{0}$, its default policy is characterized by a set of default boundaries $\left(X_{D}^{1}\left(s_{0}\right), \cdots, X_{D}^{n}\left(s_{0}\right)\right)$, and its restructuring policy is characterized by a set of restructuring boundaries $\left(X_{U}^{1}\left(s_{0}\right), \cdots, X_{U}^{n}\left(s_{0}\right)\right)$. Then, following the initial state $s_{0}$, the value of debt is

$$
\mathbf{D}\left(X ; s_{0}\right)=\sum_{j} w_{k, j}^{D}\left(s_{0}\right) \mathbf{g}_{k, j} X^{\beta_{k, j}}+\xi_{k}^{D}\left(s_{0}\right) X+\zeta_{k}^{D}\left(s_{0}\right), X \in \mathcal{D}_{k}, k=1, \cdots, 2 n-1
$$

Similarly, the value of equity is

$$
\mathbf{E}\left(X ; s_{0}\right)=\sum_{j} w_{k, j}^{E}\left(s_{0}\right) \mathbf{g}_{k, j} X^{\beta_{k, j}}+\xi_{k}^{E}\left(s_{0}\right) X+\zeta_{k}^{E}\left(s_{0}\right), X \in \mathcal{D}_{k}, k=1, \cdots, 2 n-1
$$

The coefficients $\mathbf{g}, \beta,\left(w^{D}, \xi^{D}, \zeta^{D}\right)$, and $\left(w^{E}, \xi^{E}, \zeta^{E}\right)$ are specified earlier. 
For a complete proof of Proposition 2, please see the Internet Appendix.

\section{Calibrating the Continuous-time Markov Chain}

The Markov chain for the expected growth rate and volatility of aggregate consumption is calibrated using a two-step procedure. Start with the discrete-time model of consumption and dividends in Bansal and Yaron $(2004$, BY),

$$
\begin{aligned}
g_{t+1} & =\mu_{c}+x_{t}+\sqrt{v_{t}} \eta_{t+1}, \\
g_{d, t+1} & =\mu_{d}+\phi x_{t}+\sigma_{d} \sqrt{v_{t}} u_{t+1}, \\
x_{t+1} & =\kappa_{x} x_{t}+\sigma_{x} \sqrt{v_{t}} e_{t+1}, \\
v_{t+1} & =\bar{v}+\kappa_{v}\left(v_{t}-\bar{v}\right)+\sigma_{v} w_{t+1},
\end{aligned}
$$

where $g$ is $\log$ consumption growth, $g_{d}$ is $\log$ dividend growth, and $\eta, u, e, w \sim$ i.i.d.N $(0,1)$. I use the parameters from BY, which are at the monthly frequency and are calibrated to the annual consumption data from 1929 to 1998.

The restriction that shocks to consumption $\left(\eta_{t+1}\right)$ and shocks to the conditional moments $\left(e_{t+1}, w_{t+1}\right)$ are mutually independent makes it convenient to approximate the dynamics of $(x, v)$ with a Markov chain. I first obtain a discrete-time Markov chain over a chosen horizon $\Delta$, for example, a quarter, using the quadrature method of Tauchen and Hussey (1991). For numerical reasons, I choose a small number of states $(n=9)$ for the Markov chain, with three values for $v$, and then three values of $x$ for each $v$ ( $x$ is conditionally Gaussian given $v)$. Next, I convert the grid for $(x, v)$ into a grid for $\left(\theta_{m}, \sigma_{m}\right)$ in equation (4). The calibrated values of $\left(\theta_{m}, \sigma_{m}\right)$ are reported in Table A.I. Finally, I transform the discrete-time transition matrix $\mathbf{P}=\left[p_{i j}\right]$ into the generator $\boldsymbol{\Lambda}=\left[\lambda_{i j}\right]$ of a continuous-time Markov chain using the method of Jarrow, Lando, and Turnbull (1997) (an approximation based on the assumption that the probability of more than one change of state is close to zero within the period $\Delta$ ). More details on the calibration procedure and a comparison between the simulated moments from the model and the empirical moments of consumption are available in the Internet Appendix.

Insert Table A.I About Here 


\section{REFERENCES}

Acharya, Viral V., Sreedhar T. Bharath, and Anand Srinivasan, 2007, Does industry-wide distress affect defaulted firms? Evidence from creditor recoveries, Journal of Financial Economics 85, $787-821$.

Almeida, Heitor, and Thomas Philippon, 2007, The risk-adjusted cost of financial distress, Journal of Finance 62, 2557-2586.

Altinkilic, Oya, and Robert S. Hansen, 2000, Are there economies of scale in underwriting fees? Evidence of rising external financing costs, Review of Financial Studies 13, 191-218.

Altman, Edward, Brooks Brady, Andrea Resti, and Andrea Sironi, 2005, The link between default and recovery rates: Theory, empirical evidence and implications, Journal of Business 78, $2203-2227$.

Andrade, Gregor, and Steven N. Kaplan, 1998, How costly is financial (not economic) distress? Evidence from highly leveraged transactions that became distressed, Journal of Finance 53, 1443-1493.

Asquith, Paul, Robert Gertner, and David Scharfstein, 1994, Anatomy of financial distress: An examination of junk-bond issuers, Quarterly Journal of Economics 109, 625-658.

Bansal, Ravi, and Amir Yaron, 2004, Risks for the long run: A potential resolution of asset pricing puzzles, Journal of Finance 59, 1481-1509.

Berndt, Antje, Rohan Douglas, Darrell Duffie, Mark Ferguson, and David Schranz, 2008, Measuring default risk premia from default swap rates and EDFs, Working paper, Stanford University.

Bhamra, Harjoat S., Lars-Alexander Kuehn, and Ilya A. Strebulaev, 2009, The levered equity risk premium and credit spreads: A unified framework, Review of Financial Studies (forthcoming).

Brennan, M. J., and E. S. Schwartz, 1978, Corporate income taxes, valuation, and the problem of optimal capital structure, Journal of Business 51, 103-114.

Campbell, John Y., and John H. Cochrane, 1999, By force of habit: A consumption based explanation of aggregate stock market behavior, Journal of Political Economy 107, 205-251.

Chapman, David A., 1997, The cyclical properties of consumption growth and the real term structure, Journal of Monetary Economics 39, 145-172.

Chen, Hui, 2007, Macroeconomic conditions, corporate financing decisions, and credit risk, Ph.D. Thesis, Graduate School of Business, University of Chicago.

Chen, Long, Pierre Collin-Dufresne, and Robert S. Goldstein, 2009, On the relation between the credit spread puzzle and the equity premium puzzle, Review of Financial Studies 22, 3367-3409.

Cochrane, John H., 2008, Financial markets and the real economy, in Rajnish Mehra, ed.: Handbook of the Equity Risk Premium (Elsevier, Amsterdam, Netherlands).

Davydenko, Sergei A., 2007, When do firms default? A study of the default boundary, Working Paper, University of Toronto. 
Driessen, Joost, 2005, Is default event risk priced in corporate bonds? Review of Financial Studies $18,165-195$.

Duffee, Gregory R., 1998, The relation between treasury yields and corporate bond yield spreads, Journal of Finance 53, 2225-2241.

Duffie, Darrell, 2001, Dynamic Asset Pricing Theory (Princeton University Press, Princeton and Oxford).

Duffie, Darrell, and Larry G. Epstein, 1992a, Asset pricing with stochastic differential utility, Review of Financial Studies 5, 411-436.

Duffie, Darrell, and Larry G. Epstein, 1992b, Stochastic differential utility, Econometrica 60, 353-394.

Duffie, Darrell, and David Lando, 2001, Term structures of credit spreads with incomplete accounting information, Econometrica 69, 633-664.

Duffie, Darrell, and Costis Skiadas, 1994, Continuous-time security pricing: A utility gradient approach, Journal of Mathematical Economics 23, 107-132.

Epstein, Larry G., and Stanley Zin, 1989, Substitution, risk aversion, and the temporal behavior of consumption growth and asset returns I: A theoretical framework, Econometrica 57, 937-969.

Fischer, Edwin O., Robert Heinkel, and Josef Zechner, 1989, Dynamic capital structure choice: Theory and tests, Journal of Finance 44, 19-40.

Gilson, Stuart C., 1997, Transactions costs and capital structure choice: Evidence from financially distressed firms, Journal of Finance 52, 161-196.

Goldstein, Robert, Nengjiu Ju, and Hayne Leland, 2001, An EBIT-based model of dynamic capital structure, Journal of Business 74, 483-512.

Graham, John R., 2000, How big are the tax benefits of debt? Journal of Finance 55, 1901-1941.

Hackbarth, Dirk, Jianjun Miao, and Erwan Morellec, 2006, Capital structure, credit risk, and macroeconomic conditions, Journal of Financial Economics 82, 519-550.

Hansen, Lars Peter, John C. Heaton, and Nan Li, 2008, Consumption strikes back? Measuring long-run risk, Journal of Political Economy 116, 260-302.

Huang, Jingzhi, and Ming Huang, 2003, How much of the corporate-treasury yield spread is due to credit risk? Working paper, Stanford University.

Jarrow, Robert A., David Lando, and Stuart M. Turnbull, 1997, A Markov model for the term structure of credit risk spreads, Review of Financial Studies 10, 481-523.

Jensen, Michael C., and William H. Meckling, 1976, Theory of the firm: Managerial behavior, agency costs and ownership structure, Journal of Financial Economics 3, 305-360.

Jobert, Arnaud, and L. C. G. Rogers, 2006, Option pricing with markov-modulated dynamics, SIAM Journal on Control and Optimization 44, 2063-2078.

Karatzas, Ioannis, and Steven E. Shreve, 1991, Brownian Motion and Stochastic Calculus (Springer, New York, NY). 
Korteweg, Arthur G., 2009, The net benefits to leverage, Journal of Finance (forthcoming).

Kreps, David M., and Evan L. Porteus, 1978, Temporal resolution of uncertainty and dynamic choice theory, Econometrica 46, 185-200.

Leary, Mark T., and Michael R. Roberts, 2005, Do firms rebalance their capital structures?, Journal of Finance 60, 2575-2619.

Leland, Hayne, 1994, Corporate debt value, bond covenants, and optimal capital structure, Journal of Finance 49, 1213-1252.

Leland, Hayne, 1998, Agency costs, risk management, and capital structure, Journal of Finance $53,1213-1243$.

Leland, Hayne, and Klus Bjerre Toft, 1996, Optimal capital structure, endogenous bankruptcy, and the term structure of credit spreads, Journal of Finance 51, 987-1019.

Longstaff, Francis A., Sanjay Mithal, and Eric Neis, 2005, Corporate yield spreads: Default risk or liquidity? New evidence from the credit default swap market, Journal of Finance 60, 2213-2253.

Miller, Merton H., 1977, Debt and taxes, Journal of Finance 32, 261-275.

Myers, Stewart, 1977, Determinants of corporate borrowing, Journal of Financial Economics 5, 147-175.

Pastor, Lubos, and Pietro Veronesi, 2005, Rational IPO waves, Journal of Finance 60, 1713-1757.

Piazzesi, Monika, and Martin Schneider, 2006, Equilibrium yield curves, NBER Macroeconomics Annual.

Shleifer, Andrei, and Robert W. Vishny, 1992, Liquidation values and debt capacity: A market equilibrium approach, Journal of Finance 47, 1343-1366.

Strebulaev, Ilya A., 2007, Do tests of capital structure theory mean what they say? Journal of Finance 62, 1747-1787.

Tauchen, George, and Robert Hussey, 1991, Quadrature based methods for obtaining approximate solutions to nonlinear asset pricing models, Econometrica 59, 371-396.

Weil, Philippe, 1990, Non-expected utility in macroeconomics, Quarterly Journal of Economics $105,29-42$.

Welch, Ivo, 2004, Capital structure and stock returns, Journal of Political Economy 112, 106-131. 
Table I

\section{Asset Pricing Implications of the Markov Chain Model}

The table compares the model-generated moments of the equity market with the data. The statistics of the data are from Bansal and Yaron (2004, Table IV). The expressions $E\left(r_{m}-r_{f}\right)$ and $E\left(r_{f}\right)$ are the annualized equity premium and average risk-free rate. The expressions $\sigma\left(r_{m}\right), \sigma\left(r_{f}\right)$, and $\sigma(\log (P / D))$ are the annualized volatilities of the market return, risk-free rate, and the log pricedividend ratio, respectively. The variable $E(S R)$ is the average Sharpe ratio, and $E(P / D)$ is the average price-dividend ratio for the market portfolio. The preference parameters are $\gamma=7.5$, $\psi=1.5$, and $\rho=0.015$.

\begin{tabular}{lrcr}
\hline \multirow{2}{*}{ Variable } & \multicolumn{2}{c}{ Data } & Model \\
\cline { 2 - 3 } & Estimate & SE & \\
\hline$E\left(r_{m}-r_{f}\right)$ & 6.33 & $(2.15)$ & 6.71 \\
$E\left(r_{f}\right)$ & 0.86 & $(0.42)$ & 1.47 \\
$\sigma\left(r_{m}\right)$ & 19.42 & $(3.07)$ & 16.45 \\
$\sigma\left(r_{f}\right)$ & 0.97 & $(0.28)$ & 1.20 \\
$E(S R)$ & 0.33 & & 0.41 \\
$E(P / D)$ & 26.56 & $(2.53)$ & 21.54 \\
$\sigma(\log (P / D))$ & 0.29 & $(0.04)$ & 0.23 \\
\hline
\end{tabular}


Table II

Parameters of the Model

This table reports the calibrated parameters of the model, including the parameters for the inflation process (8), debt issuance costs, tax rates, and cash flow parameters in equations (11) and (12).

\begin{tabular}{|c|c|c|c|c|c|c|}
\hline \multicolumn{3}{|c|}{ inflation } & \multicolumn{4}{|c|}{ issuance costs } \\
\hline$\pi$ & $\sigma_{P}$ & $\rho_{P, m}$ & \multicolumn{4}{|c|}{$q$} \\
\hline 0.036 & 0.014 & -0.12 & \multicolumn{4}{|c|}{0.01} \\
\hline \multicolumn{3}{|c|}{ tax rates } & \multicolumn{4}{|c|}{ cash flows } \\
\hline $\begin{array}{c}\tau_{c} \\
0.35\end{array}$ & $\begin{array}{c}\tau_{d} \\
0.12\end{array}$ & $\begin{array}{c}\tau_{i} \\
296\end{array}$ & $\bar{\theta}_{f}$ & $\bar{\sigma}_{f, m}$ & $a_{f}$ & $b_{f}$ \\
\hline
\end{tabular}


Table III

Estimating Default Losses

This table reports the target moments in Panel A and the results from the simulated method of moments estimation of the firm recovery rate $\alpha\left(s_{t}\right)$ and the idiosyncratic volatility of cash flows $\sigma_{f}$ in Panel B.

\begin{tabular}{lr}
\hline \multicolumn{2}{c}{ Panel A: Target Moments } \\
\hline 10-year default rate: & $4.9 \%$ \\
Mean recovery rate: & $41.4 \%$ \\
Volatility of recovery rates: & $9.6 \%$ \\
Correlation of recovery rates with default rates: & -0.82 \\
Correlation of recovery rates with profit growth: & 0.58 \\
\hline \multicolumn{2}{c}{ Panel B: SMM Estimates } \\
\hline$\alpha\left(s_{t}\right)=0.59-10.12 \times \theta_{m}\left(s_{t}\right)-139.05 \times \theta_{m}^{2}\left(s_{t}\right)+5.90 \times \sigma_{m}\left(s_{t}\right)$ & $\sigma_{f}=0.235$ \\
\hline
\end{tabular}




\section{Table IV \\ Dynamic Capital Structure without Business Cycle Risks}

This table reports the results of the model without business cycle risks. Three levels of market Sharpe ratio are considered. In each case, the firm recovery rate $\alpha$ and idiosyncratic volatility $\sigma_{f}$ are re-calibrated to match the debt recovery rate of $41.4 \%$ and the 10-year default probability of $4.9 \%$. The variable "10-yr credit spread" is the credit spread for a "shadow" 10-year coupon bond with identical default and recovery as the consol issued by the firm. All the results are computed at $t=0$.

\begin{tabular}{cccccc}
\hline $\begin{array}{c}\text { market } \\
\text { Sharpe ratio }\end{array}$ & $\begin{array}{c}10-\mathrm{yr} \\
\text { credit spread (bps) }\end{array}$ & $\begin{array}{c}\text { market } \\
\text { leverage (\%) }\end{array}$ & $\begin{array}{c}\text { interest } \\
\text { coverage }\end{array}$ & $\begin{array}{c}\text { net tax } \\
\text { benefit (\%) }\end{array}$ & $\begin{array}{c}\text { equity } \\
\text { Sharpe ratio }\end{array}$ \\
\hline 0.15 & 37.4 & 49.3 & 0.5 & 29.9 & 0.09 \\
0.30 & 57.0 & 50.1 & 1.3 & 11.9 & 0.19 \\
0.50 & 101.1 & 52.5 & 2.0 & 8.2 & 0.31 \\
\hline
\end{tabular}




\section{Table V \\ Dynamic Capital Structure with Business Cycle Risks}

The table reports results of the dynamic capital structure model with business cycle risks. Panel A reports the results of the full model, and Panel B considers a special case where the recovery rate $\alpha\left(s_{t}\right)$ is fixed at its unconditional mean. In each case, I solve the firm's problem at $t=0$ for all nine initial states and report the mean of these results as well as the results from state 1 (low volatility and high growth) and state 9 (high volatility and low growth). The variable "10-yr restructure freq" is the average number of debt restructurings over 10 years.

\begin{tabular}{|c|c|c|c|c|c|c|c|c|}
\hline & $\begin{array}{c}\text { debt } \\
\text { recovery rate } \\
(\%)\end{array}$ & $\begin{array}{c}10-y r \\
\text { default prob } \\
(\%)\end{array}$ & $\begin{array}{c}10-y r \\
\text { restructure } \\
\text { freq }\end{array}$ & $\begin{array}{c}10-y r \\
\text { credit spread } \\
\text { (bps) }\end{array}$ & $\begin{array}{c}\text { market } \\
\text { leverage } \\
(\%)\end{array}$ & $\begin{array}{l}\text { interest } \\
\text { coverage }\end{array}$ & $\begin{array}{c}\text { net tax } \\
\text { benefit } \\
(\%)\end{array}$ & $\begin{array}{l}\text { equity } \\
\text { Sharpe } \\
\text { ratio }\end{array}$ \\
\hline \multicolumn{9}{|c|}{ A. Benchmark Firm } \\
\hline mean & 41.8 & 5.0 & 0.48 & 104.5 & 37.4 & 2.2 & 6.2 & 0.19 \\
\hline state 1 & 52.5 & 10.5 & 0.25 & 142.7 & 50.1 & 1.1 & 7.3 & 0.16 \\
\hline state 9 & 15.0 & 4.2 & 0.65 & 121.4 & 32.1 & 3.7 & 4.7 & 0.27 \\
\hline \multicolumn{9}{|c|}{ B. Constant Firm Recovery Rate } \\
\hline mean & 45.4 & 17.0 & 0.52 & 203.0 & 53.6 & 1.3 & 11.4 & 0.19 \\
\hline state 1 & 46.5 & 16.3 & 0.47 & 168.7 & 54.7 & 0.9 & 12.2 & 0.16 \\
\hline state 9 & 43.3 & 19.8 & 0.59 & 282.1 & 53.7 & 1.8 & 10.3 & 0.28 \\
\hline
\end{tabular}


Table VI

\section{Decomposing the Effects of Business Cycle Risks on Capital Structure}

This table decomposes the effects of business cycle risks on the capital structure and credit spreads. Panel A considers a firm whose systematic volatility of cash flows is zero. Panel B considers a firm with idiosyncratic volatility $\sigma_{f}=0.153$, which lowers its average 10-year default probability to $0.6 \%$ and makes its cash flows more correlated with the market.

\begin{tabular}{|c|c|c|c|c|c|c|c|c|}
\hline & $\begin{array}{c}\text { debt } \\
\text { recovery rate } \\
(\%)\end{array}$ & $\begin{array}{c}10-y r \\
\text { default prob } \\
(\%)\end{array}$ & $\begin{array}{l}10-\mathrm{yr} \\
\text { restructure } \\
\text { freq }\end{array}$ & $\begin{array}{c}10-\mathrm{yr} \\
\text { credit spread } \\
\text { (bps) }\end{array}$ & $\begin{array}{c}\text { market } \\
\text { leverage } \\
(\%)\end{array}$ & $\begin{array}{l}\text { interest } \\
\text { coverage }\end{array}$ & $\begin{array}{c}\text { net tax } \\
\text { benefit } \\
(\%)\end{array}$ & $\begin{array}{c}\text { equity } \\
\text { Sharpe } \\
\text { ratio }\end{array}$ \\
\hline \multicolumn{9}{|c|}{ A. Jump-risk Premium } \\
\hline mean & 40.1 & 4.9 & 0.40 & 65.0 & 32.9 & 1.0 & 12.8 & 0.09 \\
\hline state 1 & 43.6 & 5.3 & 0.38 & 55.3 & 33.9 & 0.8 & 13.0 & 0.13 \\
\hline state 9 & 15.7 & 3.9 & 0.57 & 63.4 & 28.9 & 1.7 & 11.7 & 0.16 \\
\hline \multicolumn{9}{|c|}{ B. Correlation with the Market } \\
\hline mean & 41.5 & 0.6 & 0.51 & 38.0 & 37.0 & 2.5 & 5.8 & 0.24 \\
\hline state 1 & 52.7 & 1.2 & 0.32 & 45.1 & 43.7 & 1.5 & 6.6 & 0.21 \\
\hline state 9 & 14.6 & 0.7 & 0.67 & 54.9 & 33.5 & 4.0 & 4.6 & 0.32 \\
\hline
\end{tabular}


Table A.I

States of the Markov Chain

This table reports the pairs of values for the conditional volatility $\sigma_{m}\left(s_{t}\right)$ and expected growth rate of aggregate consumption $\theta_{m}\left(s_{t}\right)$ for the states $s_{t}=1, \cdots, 9$ of the calibrated Markov chain.

\begin{tabular}{|c|c|c|}
\hline \multicolumn{3}{|c|}{$\left(\sigma_{m}\left(s_{t}\right), \theta_{m}\left(s_{t}\right)\right)$} \\
\hline 1. $(0.021,0.041)$ & 2. $(0.027,0.048)$ & 3. $(0.032,0.053)$ \\
\hline 4. $(0.021,0.018)$ & 5. $(0.027,0.018)$ & 6. $\left(\begin{array}{lll}0.032, & 0.019)\end{array}\right.$ \\
\hline 7. $(0.021,-0.004)$ & 8. $(0.027,-0.011)$ & 9. $(0.032,-0.016)$ \\
\hline
\end{tabular}




\section{A. Default rates and credit spreads}

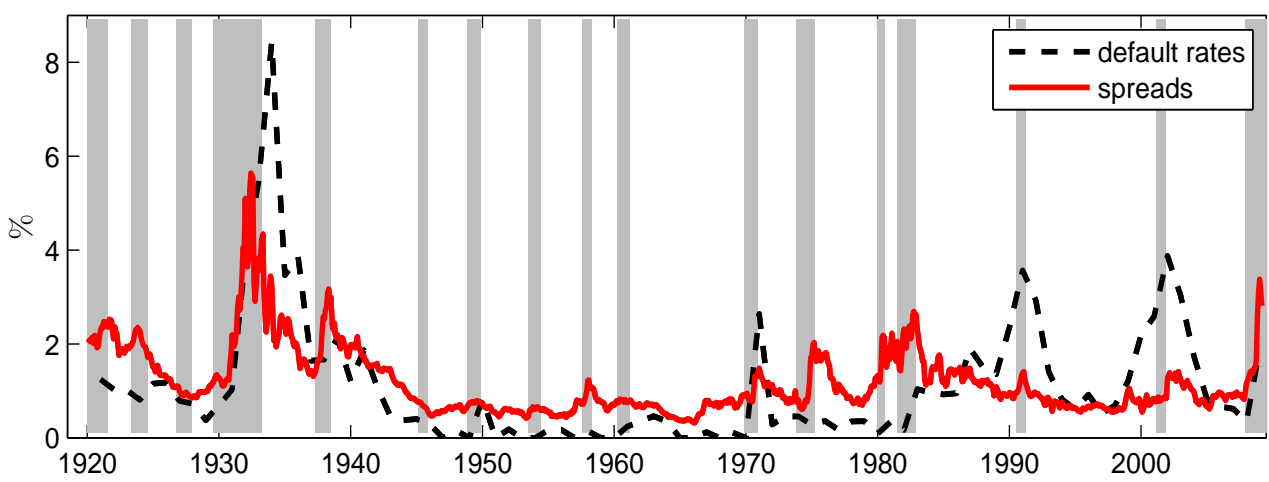

B. Recovery rates

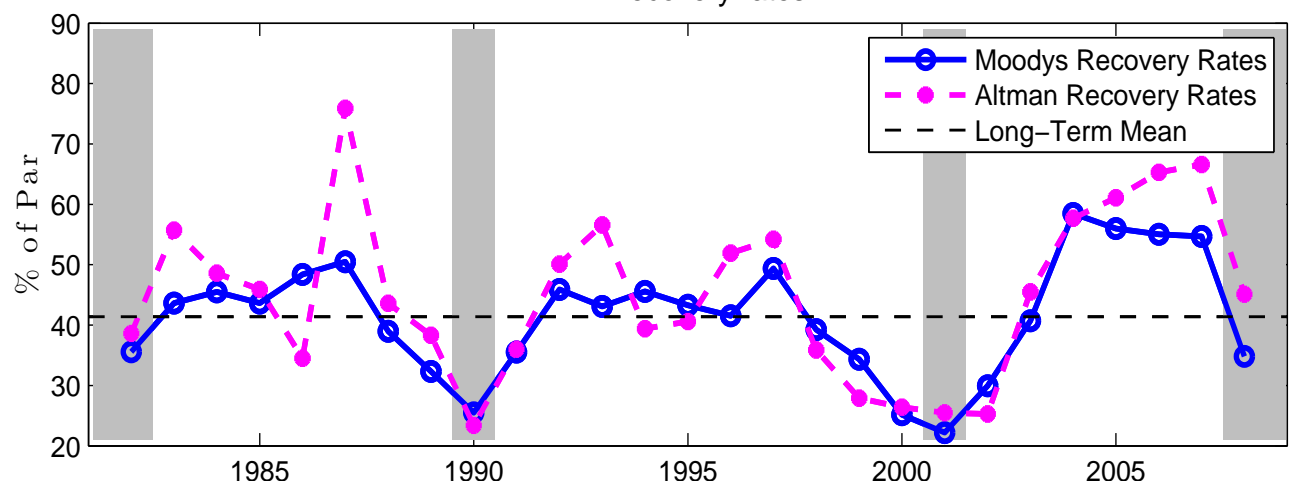

Figure 1. Default rates, credit spreads, and recovery rates over the business cycle. Panel A plots the Moody's annual corporate default rates during 1920 to 2008 and the monthly Baa-Aaa credit spreads during 1920/01 to 2009/02. Panel B plots the average recovery rates during 1982 to 2008. The "Long-Term Mean" recovery rate is 41.4\%, based on Moody's data. Shaded areas are NBER-dated recessions. For annual data, any calendar year with at least five months being in a recession as defined by NBER is treated as a recession year. 

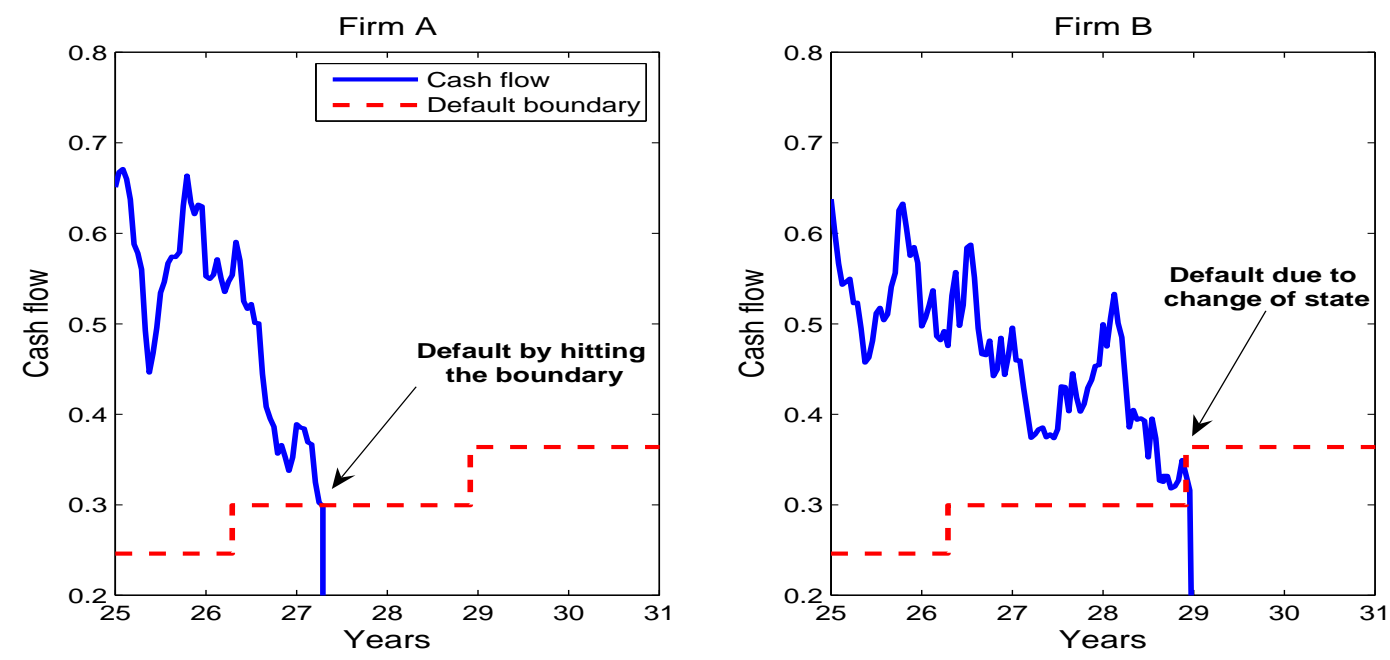

Figure 2. Illustration of two types of defaults. In the left panel, default occurs when the cash flow drops below a default boundary; in the right panel, default occurs when the default boundary jumps up, which is triggered by a change of aggregate state. 
A. Stationary distribution

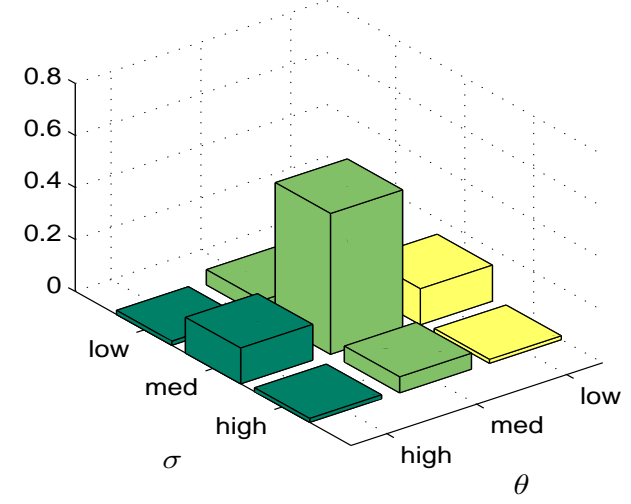

C. Jump-risk premium: $\exp (\kappa(5, j))$

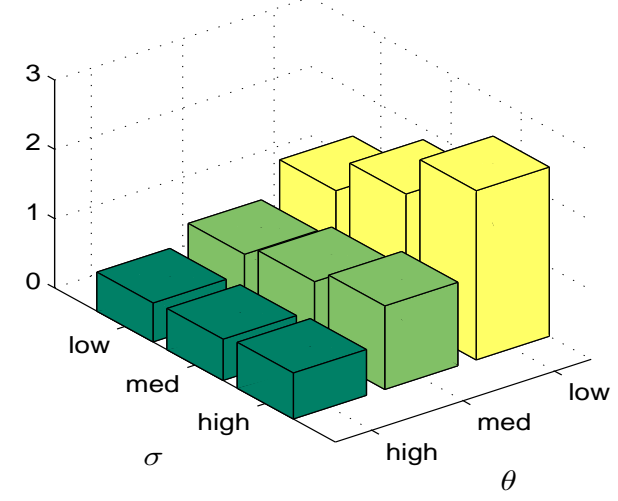

B. Risk-free rate: $r\left(s_{t}\right)$

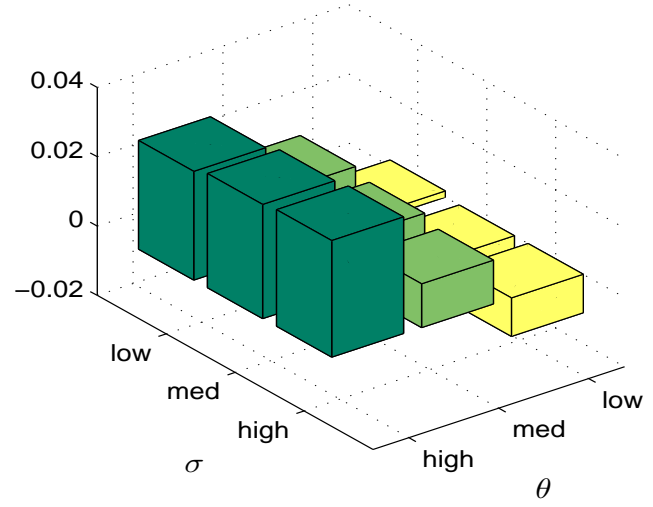

D. Firm recovery rate: $\alpha\left(s_{t}\right)$

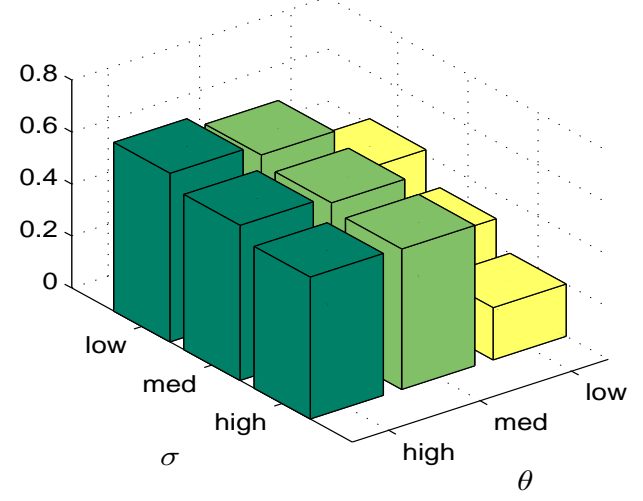

Figure 3. Stationary distribution of the Markov chain, risk-free rate, jump-risk premium, and firm recovery rate. Panel A plots the stationary distribution of the Markov chain. Panels B through D plot the value of the risk-free rate, jump-risk premium, and firm recovery rate in the nine states with different values for the expected growth rate $(\theta)$ and conditional volatility $(\sigma)$. 


\section{A. Optimal coupon: $C\left(s_{0}\right)$}

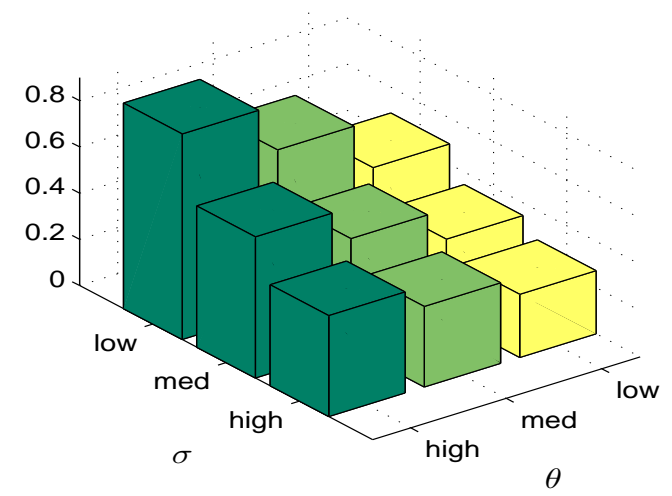

C. Default boundary: $X_{D}^{s_{t}}(5)$

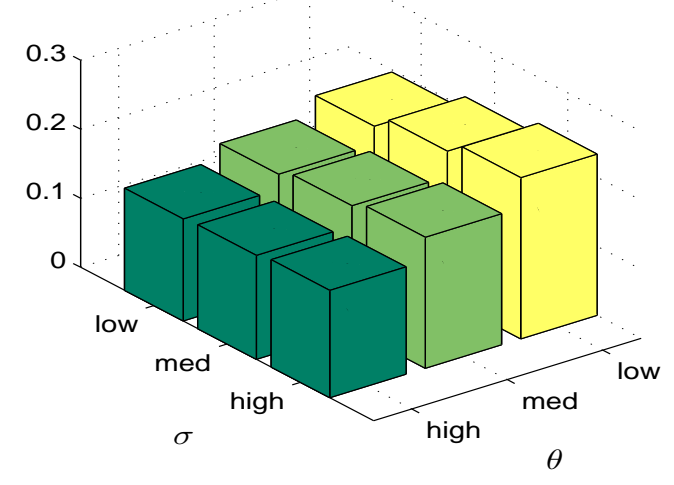

E. Asset value at default

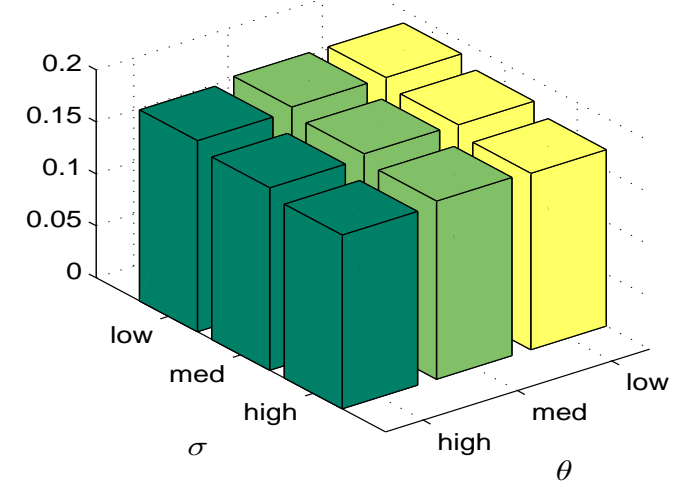

B. Optimal leverage: $D /(D+E)$

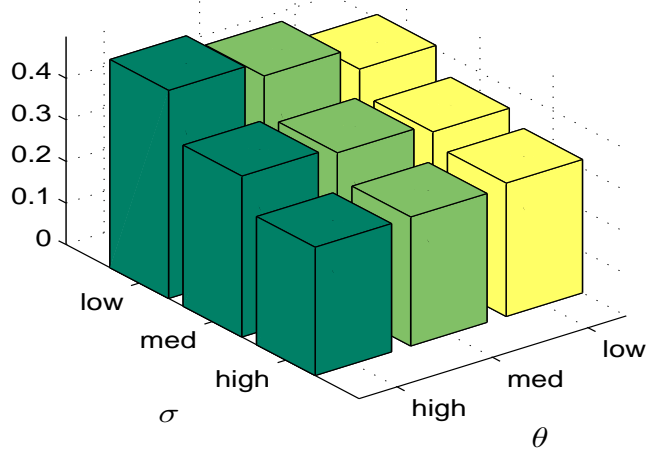

D. Restructuring boundary: $X_{U}^{s_{t}}(5)$

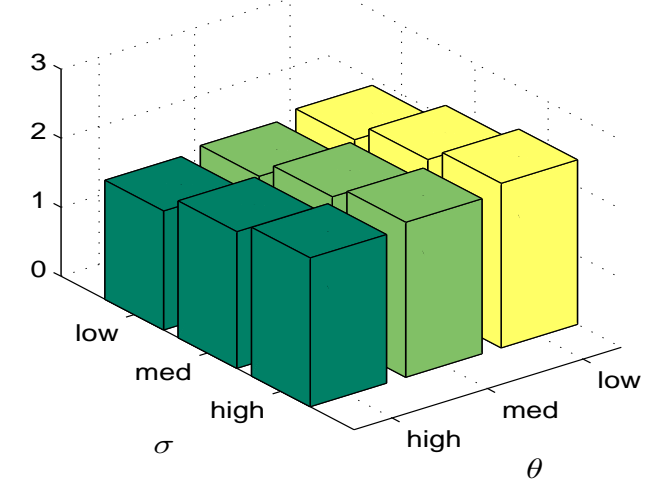

F. Default losses: $L / E_{U}$

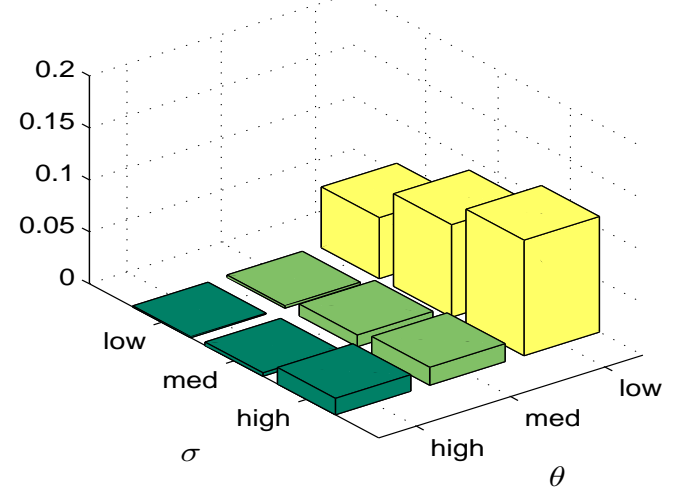

Figure 4. Optimal capital structure, default/restructuring boundaries, asset value at default, and default losses. Panels $\mathrm{A}$ and $\mathrm{B}$ plot the optimal coupon and leverage ratio the firm chooses in each initial state. Conditional on initial state $s_{0}=5$, Panels $\mathrm{C}$ through $\mathrm{F}$ plot the optimal default and restructuring boundaries, asset value at default (relative to initial asset value), and default losses (relative to initial firm value) in different states. Initial cash flow $X_{0}=1$. 
A. Benchmark firm

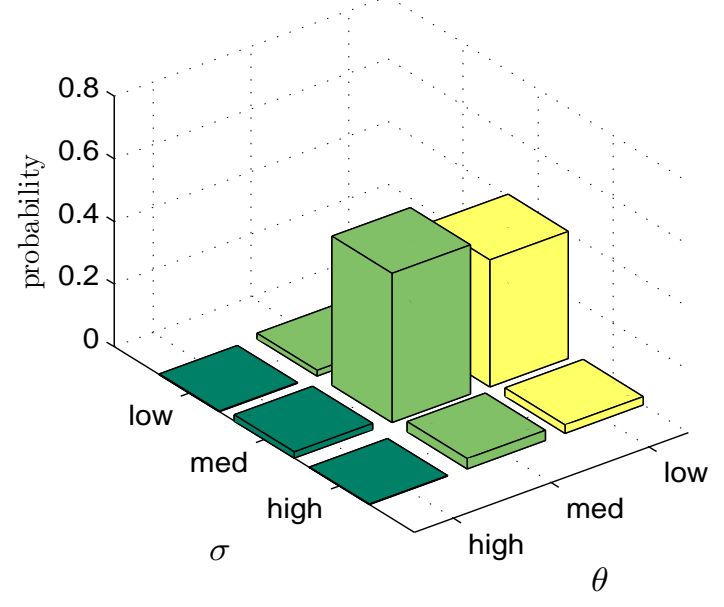

B. High correlation with market

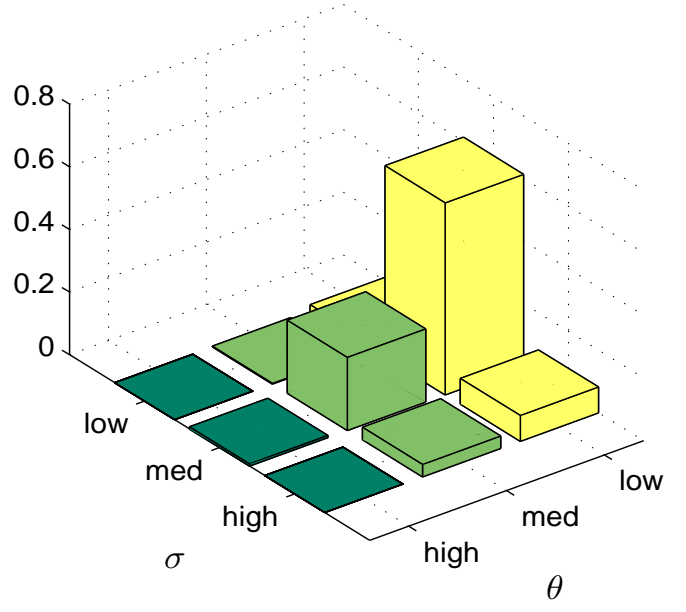

Figure 5. Distribution of defaulting states (conditional on default within 10 years). Panel A considers the benchmark firm. Panel B considers a firm whose cash flows have higher correlation with the market. In both cases, the initial state is $s_{0}=5$. 
A. Time series of market leverage

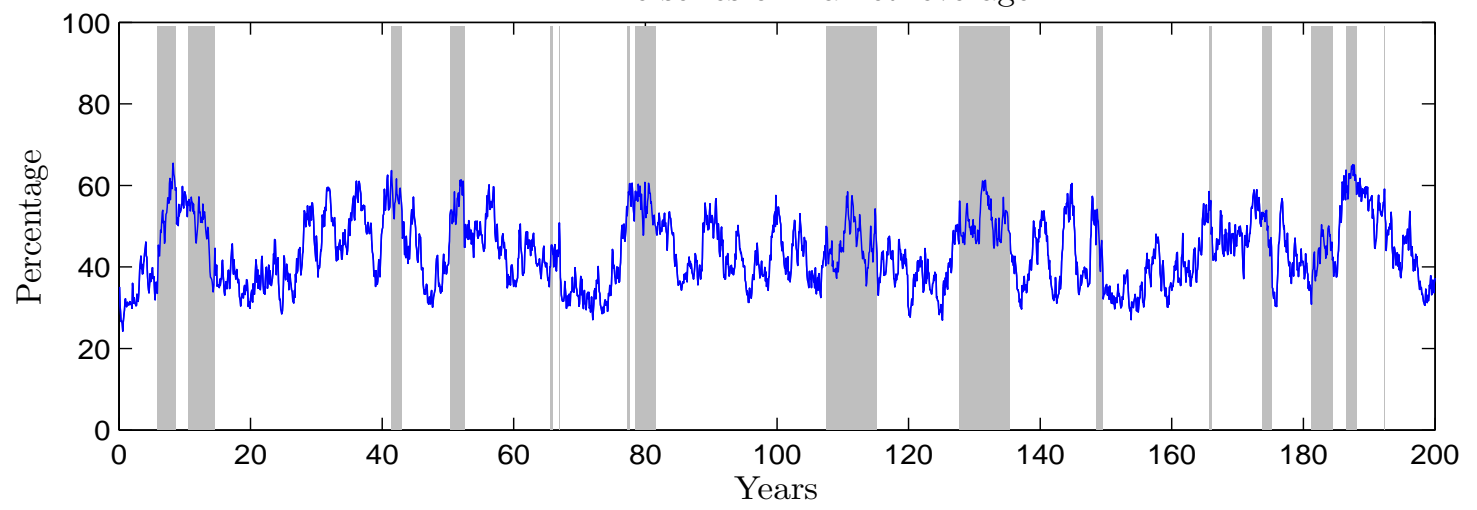

B. Monthly default rates

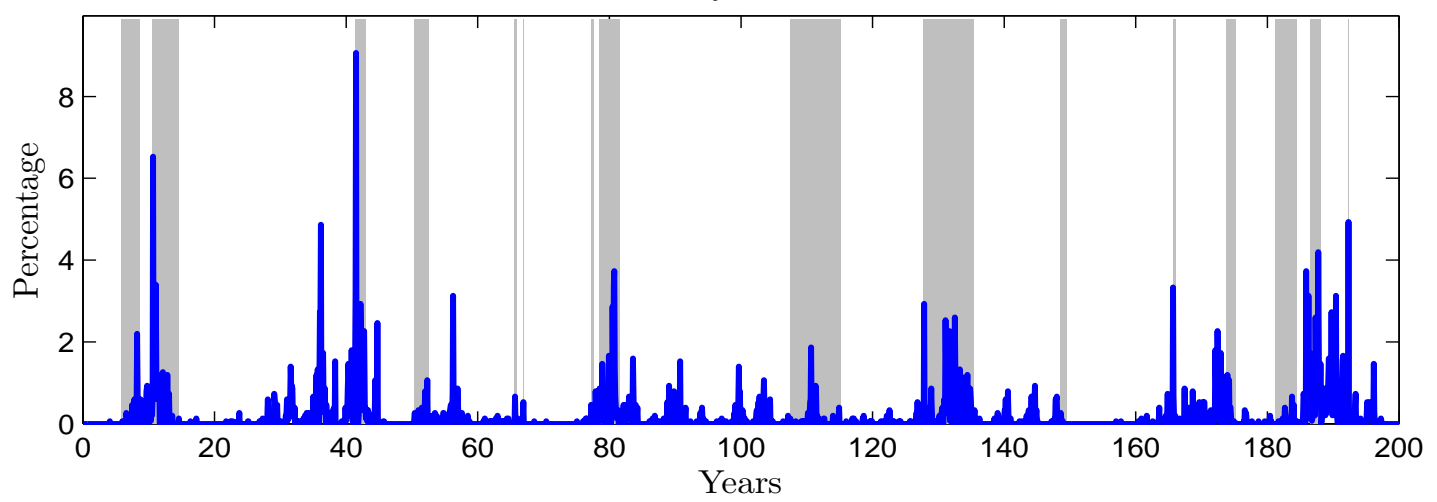

Figure 6. Simulated aggregate leverage ratio and monthly default rates. This figure plots the time series of aggregate market leverage and monthly default rates from a simulation of 1,000 firms over 200 years. Shaded areas denote the times when the economy is in a state with negative expected output growth. 


\section{Notes}

${ }^{1}$ Moody's recovery rates are from Moody's "Corporate default of recovery rates, 1920-2008." Moody's determines recovery rates using closing bid prices on defaulted bonds observed roughly 30 days after the default date. For robustness, I also plot the value-weighted recovery rates from the "Altman High-yield bond default and return report," which measures recovery rates using closing bid prices as close to the default date as possible.

${ }^{2}$ Suppose the true 10-year default probability for a firm is $0.5 \%$. Assuming risk neutrality, if the estimated default probability is $1 \%$ higher than the true value, it will result in a $200 \%$ increase in the predicted spread.

${ }^{3}$ A recent paper by Elkamhi, Ericsson, and Parsons (2009, EEP) computes the ex ante default losses using the risk-neutral default probabilities and default boundaries implied by the structural model of Leland and Toft (1996) and a constant default loss estimate from Andrade and Kaplan (1998). EEP find that even after the risk adjustments, the ex-ante distress costs are still too low to explain the level of leverage. I show that introducing macroeconomic risks to the structural model can substantially raise the ex ante default losses.

${ }^{4}$ Welch (2004) documents that firms do not actively adjust their debt levels in response to changes in the market value of equity. Leary and Roberts (2005) provide empirical evidence that such behavior is likely due to adjustment costs, and Strebulaev (2007) shows that a trade-off model with lumpy adjustment costs can account for such effects. Alternatively, Chen (2007) assumes that all bonds issued have a pari passu covenant, and that the debt issuance costs are "quasi-fixed," that is, they are a fraction $q$ of the amount of debt outstanding after issuance. These two ways of modeling debt issuance generate very similar results.

${ }^{5}$ This assumption does not imply that debt holders cannot lever up again after taking over the firm's assets. It is simply a convenient way to model the value of debt at default.

${ }^{6}$ This assumption implies that equity holders can commit to the time of future restructure $\mathcal{T}_{U}$. The results are similar if they cannot commit to $\mathcal{T}_{U}$.

${ }^{7}$ Approximating the BY model with a two-state Markov chain would require that the states be far apart and much more persistent than the business cycles. This means the economy would always be in one of the two extreme states (good or bad), which would influence firms' decisions. A two-state model also does not separate the effects of time-varying growth rates from volatility.

${ }^{8}$ This leverage ratio already takes into account the effect that the option to restructure its debt in the future leads firms to take on less debt now (see Goldstein, Ju, and Leland (2001)). In the static version of this model, the optimal leverage is $59.6 \%$.

${ }^{9}$ Korteweg (2009) estimates the net benefit of leverage by exploiting its relationship with the firm's market value, beta, equity, and debt, assuming that asset beta is the same within an industry.

${ }^{10}$ This definition of default loss is slightly biased upward. If default coincides with the arrival of a large shock (as illustrated in Figure 2, Panel B), the cash flow at default will be below the default boundary for the corresponding state, which implies a smaller default loss. 